\title{
AGEING EFFECTS ON THE YIELDING CHARACTERISTICS OF CEMENT-MIXED GRANULAR MATERIALS
}

\author{
Alan Ezaoui ${ }^{\text {i) }}$, Fumio Tatsuoka ${ }^{\text {ii) }}$, Yusuke Sano ${ }^{\text {iii)}}$, Yusuke Iguchi ${ }^{\text {iv) }}$, \\ Yohei Maeda ${ }^{\text {iv) }}$, Yuta SASAKI ${ }^{\text {v) }}$ and Antoine DutTine ${ }^{\text {vi) }}$
}

\begin{abstract}
Ageing effects on the elasto-viscoplastic property of compacted moist cement-mixed granular material (GM) were evaluated by performing a series of non-standard drained triaxial compression (TC) tests. Two types of GM, crushed gravelly soil from a quarry and crushed concrete aggregate (i.e., a recycled material), were used. The specimens were produced by moist-compaction and then cured at constant water content under unstressed conditions for seven days. They were re-cured basically for two days under different stress states during otherwise drained TC loading at a constant strain rate. Yielding characteristics upon the restart of drained monotonic loading (ML) at a constant strain rate toward ultimate failure at the same or increased or decreased confining pressure were evaluated. The stress-strain behaviour before the stress state reaches the current yield locus is very stiff and highly reversible. Unlike elasto-plastic materials exhibiting no ageing effects, the yield locus expands during sustained loading at a fixed effective stress state due to not only yielding associated with creep deformation, controlled basically by the viscous property, but also ageing, controlled basically by time-elapsing. The shape and location of current yield locus depends on the location of the current stress state relative to the current ultimate failure envelope. The observed yield characteristics were analyzed based on a newly introduced interactive double-yield concept while in the framework of the non-linear threecomponent elasto-viscoplastic model that takes into account ageing effects as well as an interaction between ageing and inviscid yielding (and its potential decay by irreversible straining). The trends of stress-strain-time behaviour observed with the two types of cement-mixed GMs are essentially the same.
\end{abstract}

Key words: ageing, cement-mixing, elasto-viscoplastic properties, granular materials, triaxial compression test, viscous property, yield locus (IGC: D6/D7)

\section{INTRODUCTION}

Cement-mixing of soil is now one of the established and widely-used ground improvement technologies. The different methods currently used in practice include the following: i) mixing-in-place of soft clay without compaction (i.e., the Deep Mixing Method); ii) placing of cement-mixed soil slurry without compaction at on-shore sites or off-shore under-water sites (e.g., huge off-shore embankments for the Trans-Tokyo Bay Highway; Tatsuoka et al., 2000); iii) roller-compacted concrete (RCC) by high compaction of cement-mixed gravelly soil to construct high concrete dams (e.g., Schrader, 1996); and more recently iv) the use of cement-mixed gravelly soil to construct bridge abutments, compacted at an energy level lower than the one used for RCC (Watanabe et al., 2003; Tatsuoka et al., 2005, 2009). Despite the above, only a limited number of studies have been conducted to ex- perimentally evaluate and formulate the yielding characteristics (pre-peak and post-peak), affected by ageing, of cement-mixed granular material (GM).

The first objective of the present study is therefore to understand the yielding characteristics of cement-mixed GM, which is essential for more confident use of cementmixed GM as the backfill for critical civil engineering structures allowing limited deformation, such as bridge abutments for high-speed trains. As long as the inviscid stress state remains inside the pseudo-elastic zone for a given cyclic loading history that may be experienced by such structures as described above, it is likely that strain increments are kept rather small and nearly reversible and therefore only small residual strains develop. Yet, experimental studies by performing relevant cyclic loading tests will be necessary to obtain any distinct conclusion in this respect. The second objective is to show that the stress-strain-time behaviour of cement-mixed crushed

i) Post-doctorial Fellow, Department of Civil Engineering, Tokyo University of Science, Japan.

ii) Professor, ditto (tatsuoka@rs.noda.tus.ac.jp).

iii) Kyosei-kiko Co. Ltd. (formerly, Graduate Student, ditto).

iv) Chemical Grouting Co. Ltd. (formerly, Graduate Student, ditto).

v) Graduate Student, ditto.

vi) Assistant Professor, ditto.

The manuscript for this paper was received for review on October 22, 2009; approved on May 19, 2010.

Written discussions on this paper should be submitted before May 1, 2011 to the Japanese Geotechnical Society, 4-38-2, Sengoku, Bunkyo-ku, Tokyo 112-0011, Japan. Upon request the closing date may be extended one month. 
Table 1. Two components of time effects (Tatsuoka et al., 2003, $2008 b, c)$

\begin{tabular}{|c|c|c|c|c|}
\hline & Phenomenon & Mechanism & Parameter & \\
\hline \multirow{3}{*}{ 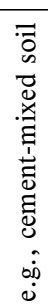 } & Ageing effect & $\begin{array}{l}\text { Time-dependent } \\
\text { changes in the intrin- } \\
\text { sic material property }\end{array}$ & $\begin{array}{l}\text { Time with } \\
\text { a fixed } \\
\text { origin }\left(t_{\mathrm{c}}\right)\end{array}$ & \\
\hline & Apparent ageing & & & $\stackrel{\square}{\square}$ \\
\hline & $\begin{array}{l}\text { Loading rate effect } \\
\text { (creep, stress } \\
\text { relaxation, etc.) }\end{array}$ & Material viscosity & $\begin{array}{l}\text { strain rate, } \\
\dot{\varepsilon}^{\text {ir }}\end{array}$ &  \\
\hline
\end{tabular}

+) Positive (e.g., cementation) or negative (e.g., weathering)

*) Not including geological effects

concrete aggregate, a recycled material, is essentially the same as that of the cement-mixture of a natural gravelly soil that is used as the backfill material of highest quality and, therefore, the former can be used such a backfill material as the latter (Tatsuoka, 2004).

\section{DEFINTION OF AGEING EFFECT AND A BRIEF REVIEW OF ITS STUDY}

The time effects, which affect the yielding characteristics of cement-mixed GM, comprise the following two components (Table 1; Tatsuoka et al., 2003, 2008b, c):

a) Ageing effects: defined as time-dependent changes in the intrinsic stress-strain properties, including peak strength, elasticity, yielding and viscous properties. The ageing effects can be expressed as a function of time $\left(t_{c}\right)$ having a specifically defined origin.

b) Loading rate effects: defined as the rate-dependency of stress-strain behaviour due to the viscous property, typically noted by creep deformation, stress-relaxation and strain rate effects on stress-strain behaviour. The viscous property is basically a function of instantaneous irreversible (or visco-plastic) strain rate tensor and other relevant parameters (i.e., instantaneous stress-state, loading history parameters, etc.), and not time (Di Benedetto et al., 2002, 2005; Tatsuoka et al., 2002, 2003, 2008a; Tatsuoka, 2004, 2007).

These two time effect components are controlled by, and interact with, many other parameters, for example, state variables (temperature, water content and others) and their given changes with time. Furthermore, ageing and viscous effects may interact with each other.

The classical elasto-plastic models in essence cannot describe the ageing effects and the loading rate effects due to the viscous property. On the other hand, it is often important and necessary to take into account these time effects for proper analysis and prediction of ground deformation and structural displacements. To this end, the authors and their colleagues attempted the following two steps of development:

1) Extension of elasto-plastic modeling toward elastoviscoplastic modeling.

2) Modification of elasto-viscoplastic models to take into account ageing effects.

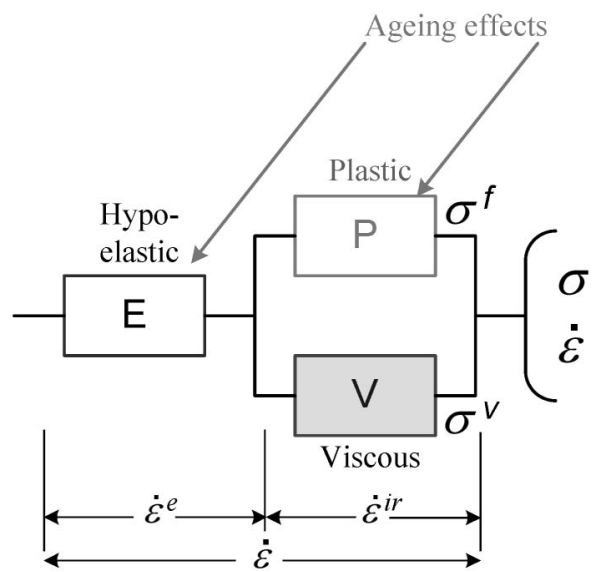

Fig. 1. Non-linear three-component model framework (Di Benedetto et al., 2002; Tatsuoka et al., 2002) directly incorporating ageing effects on elastic component " $E$ " and plastic component " $P$ ",

For the first step, Di Benedetto et al. (2002) and Tatsuoka et al. (2002, 2008a) showed that the viscous property of geomaterial can be smoothly incorporated into a relevant elasto-plastic model by adding a viscous component (i.e., $\mathrm{V}$ body in Fig. 1) following the non-linear three-component model framework.

For the second step, a number of previous experimental studies on the ageing effect by cement-hydration on the strength and deformation characteristics of cementmixed soil (e.g., Kawasaki et al., 1978; Terashi et al., 1980; Tatsuoka and Kobayashi, 1983; Barbosa-Cruz and Tatsuoka, 2000) were reviewed. In most of these studies, the specimens were cured under unconfined conditions. In comparison, the study on the effects of creep deformation and ageing effects that take place during curing under a fixed pressure-confined and shear-stressed condition on the subsequent stress-strain behaviour of chemical-stabilized soil is very limited (e.g., Sugai and Tatsuoka, 2003; Kongsukprasert and Tatsuoka, 2005; Kongsugprasert et al., 2007; Åhnberg, 2007; Dalla Rosa et al., 2008). Tatsuoka et al. $(2003,2008 \mathrm{~b}, \mathrm{c})$ and Tatsuoka (2007) proposed to incorporate not only effects of the previous ageing process, but also those of the developing process of ageing during arbitrary loading histories, including multiple-staged sustained loading (SL) at different stress states and monotonic loading at different and varying strain rates, into the non-linear three-component model (Fig. 1). To that end, they modified the basic yield function for P body (Fig. 1), which may be basically the same as those employed in classical elasto-plastic models, by incorporating:

1) An ageing function that describes time-dependent changes in the inviscid strength and deformation properties;

2) An interaction function that describes interaction effects between inviscid yielding and ageing effects as a function of loading history; and

3) A damage function that describes the damage to the positive interaction effect by subsequent irreversible straining. 
Tatsuoka (2007) and Tatsuoka et al. (2008b, c) proposed a revised model relevant only along a stress path at a fixed confining pressure and reported its experimental validation. To develop a model that can be applied to general stress states and stress paths, the effects of ageing on the location and shape of yield locus on the stress plane, or yield surface in the stress space, should be known. The authors studied this issue by performing a systematic drained triaxial compression (TC) tests on compacted moist cement-mixed specimens of two types of granular materials. Related considerations on the theoretical framework for modeling and some theoretical analysis of the test results are also presented in this paper. A more detailed theoretical development of the model is beyond the scope of this paper and will be reported by the authors in the near future.

\section{ELASTO-VISCOPLASTIC FRAMEWORK AND AGEING}

\section{Non Linear Three-component Model}

To evaluate, based on the experimental data, the ageing effects on the yielding characteristics described in terms of inviscid stresses, which is one of the basic plastic properties, it is necessary to note that measured stresses are total stresses, including the viscous effects that are always coupled with the plastic behaviour (Di Benedetto et al., 2002; Tatsuoka et al., 2002). For this reason, it is imperative to analyze the measured total stress-strain relations based on a relevant elasto-viscoplastic model. That is, the relevant interpretation of given experimental data becomes possible only by properly taking into account the effects of viscous property on the observed ratedependent yielding characteristics. For the same reason, it is necessary to control the loading rate in the experiments. These issues are discussed more in detail later referring to Fig. 13 and others. In the present study, the non-linear three-component model (Fig. 1) was employed as the framework to analyze the experimental data taking into account the effects of viscous property on observed stress-strain behaviour. It has been shown that, when the confining pressure is fixed and only a single stress parameter is variable (e.g., the deviator stress or the principal stress ratio), this model can accurately simulate elasto-viscoplastic behaviour of a wide variety of geomaterials not exhibiting ageing effects during and after complex and arbitrary loading histories (Tatsuoka et al., 2002, 2008a; Di Benedetto et al., 2002; Kongkitkul et al., 2008). Moreover, the model can easily incorporate ageing effects via those on elastic and plastic components (Tatsuoka et al., 2008b, 2008c). The model is only briefly described below, as its detailed description under general stress conditions is not the primary purpose of this paper. According to this model, the total (or measured) effective stress tensor $\sigma$ can be decomposed into an inviscid stress tensor $\sigma^{\mathrm{f}}$ (plastic body $\mathrm{P}$ ) and a viscous stress tensor $\sigma^{\mathrm{v}}$ (viscous body $\mathrm{V}$ ) and it is also the case with the respective stress components. The strain increment tensor $d \varepsilon$ is divided into an elastic part $d \varepsilon^{\mathrm{e}}$ (reversible increment strain tensor) and a visco-plastic part $d \varepsilon^{\text {ir }}$ (irreversible strain tensor) and it is also the case with the respective strain components. That is, the basic equations that control the stress-strain behaviour are:

$$
\begin{aligned}
& \sigma=\sigma^{\mathrm{f}}+\sigma^{\mathrm{v}} \\
& d \varepsilon=d \varepsilon^{\mathrm{e}}+d \varepsilon^{\mathrm{ir}}
\end{aligned}
$$

Under monotonic loading conditions (i.e., $\dot{\varepsilon}^{\text {ir }}>0$ ) along a fixed stress path, $\sigma^{\mathrm{f}}$ is a unique function of $\varepsilon^{\mathrm{ir}}$. When the viscous property is the Isotach type (Tatsuoka et al., 2002; Di Benedetto et al., 2002), then $\sigma^{\mathrm{v}}$ is a unique function of $\varepsilon^{\text {ir }}$ and its rate while it is linked to $\sigma^{\text {f via a }}$ monotonous viscous function $g_{\mathrm{v}}$ of irreversible strain rate $\dot{\varepsilon}^{\text {ir }}$, as:

$$
\begin{aligned}
& \sigma^{\mathrm{v}}=\sigma^{\mathrm{f}} \cdot g_{\mathrm{v}}\left(\dot{\varepsilon}^{\mathrm{ir}}\right) \\
& g_{\mathrm{v}}\left(\dot{\varepsilon}^{\mathrm{ir}}\right)=\alpha\left[1-\exp \left\{1-\left(\frac{\left|\dot{\varepsilon}^{\mathrm{ir}}\right|}{\dot{\varepsilon}_{\mathrm{r}}^{\text {ir }}}+1\right)^{\mathrm{m}}\right\}\right]
\end{aligned}
$$

where $\alpha, \mathrm{m}$ and $\dot{\varepsilon}_{\mathrm{r}}^{\text {ir }}$ are the three constants. On the other hand, to describe the other viscous property types (i.e., TESRA, Combined and $\mathrm{P}$ and $\mathrm{N}$ ), effects of previous loading history need to be taken into account by introducing the decay function $g_{\text {decay }}$, which is a function of the current irreversible strain and a strain history parameter controlling the decay rate, as described in details by Di Benedetto et al. (2002) and Tatsuoka et al. (2002, 2008a). The previous studies (Kongsukprasert and Tatsuoka, 2007; Tatsuoka et al., 2008b) showed that the viscous property of the cement-mixed gravelly soil used in the present study is the Isotach type in the pre-peak regime while it changes toward the TESRA type in the postpeak regime. In the following part of this paper, as only the yielding characteristics of cement-mixed GM in the pre-peak regime is analyzed, only the Isotach type viscous property is dealt with. However, the theoretical framework presented below can be equally applied to the other viscous property types after some necessary modifications.

Benedetto et al. (2002) and Tatsuoka et al. (2002) showed that, for the generalization of Eqs. (1) to (3) to general stress conditions, the stress parameter, $\sigma$, should be the ratio of the (effective) major and minor principal stresses, $\sigma_{1} / \sigma_{3}$, for unbound granular materials (GMs). For bound GMs, including the cement-mixed GMs used in the present study, as illustrated in Fig. 2, it is necessary to introduce the cohesion term $c^{*}$ into the total, inviscid and viscous stress components to consistently keep the framework of Eq. (3) (Kongsukprasert et al., 2007). Then Eqs. (1) and (3) become:

$$
\begin{aligned}
& R_{\text {eq }}=\frac{\sigma_{1}+c^{*}}{\sigma_{3}+c^{*}}=\frac{\sigma_{1}^{\mathrm{f}}+\sigma_{1}^{\mathrm{v}}+c^{*}}{\sigma_{3}^{\mathrm{f}}+\sigma_{3}^{\mathrm{v}}+c^{*}}=R_{\text {eq }}^{\mathrm{f}}+R_{\text {eq }}^{\mathrm{v}} \\
& R_{\text {eq }}^{\mathrm{f}}=\frac{\sigma_{1}^{\mathrm{f}}+c^{*}}{\sigma_{3}^{\mathrm{f}}+c^{*}} \\
& R_{\text {eq }}^{\mathrm{v}}=R_{\text {eq }}^{\mathrm{f}} \cdot g_{\mathrm{v}}\left(\left\|\dot{\underline{\dot{\varepsilon}}}^{\mathrm{i}}\right\|\right)=\left(\frac{\sigma_{1}^{\mathrm{f}}+c^{*}}{\sigma_{3}^{\mathrm{f}}+c^{*}}\right) \cdot g_{\mathrm{v}}\left(\| \underline{\underline{\dot{\varepsilon}^{\mathrm{i}}} \|}\right)
\end{aligned}
$$

where $\left\|\underline{\underline{\dot{\varepsilon}^{\mathrm{ir}}}}\right\|$ is the norm of the irreversible strain rate ten- 


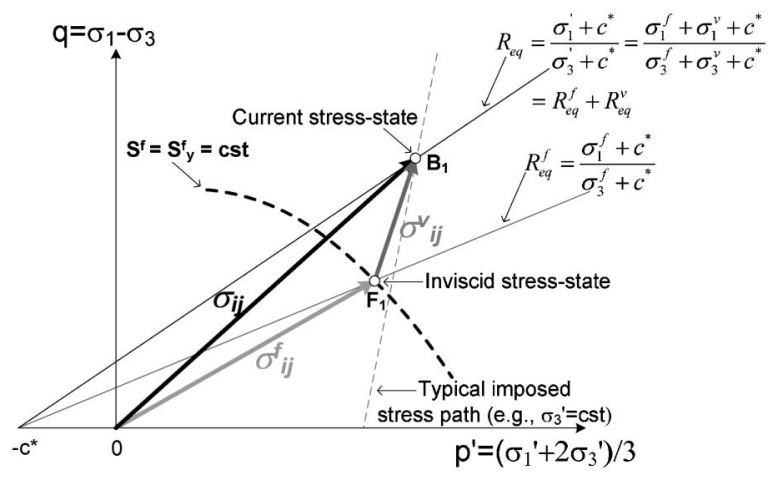

Fig. 2. Stress parameters describing elasto-visco plastic behaviour of geomaterial with ageing effect; $c^{*}=0$ for unbound geomaterial

sor. It is to be noted that $R_{\text {eq }}^{\mathrm{v}}$ is not equal to $\left(\sigma_{1}^{\mathrm{v}}+c^{*}\right) /$ $\left(\sigma_{3}^{v}+c^{*}\right)$. In the present study, it is assumed that the viscosity function $g_{\mathrm{v}}$ (Eq. (4)) is not affected by ageing, while the elastic and plastic stress-strain properties respectively of $\mathrm{E}$ and $\mathrm{P}$ bodies (Fig. 1) are affected by ageing. Interactions between ageing effects (as a function of time $t_{c}$ ) and the yielding of plastic body $\mathrm{P}$ are taken into account, as described in Tatsuoka et al. (2008b) and later in this paper.

\section{Characteristic Zones}

It is understood that, upon the restart of loading from a stationary condition, the instantaneous tangent stiffness starts notably decreasing from the maximum value when the loading stress path exceeds the boundary of a zone in which the strain is very small and highly reversible (i.e., quasi-elastic). By subsequent loading, the tangent shear stiffness may decrease drastically when large-scale yielding starts taking place even when well before the peak stress state or critical state. To properly describe such continuous and smooth changes in the stress-strain behaviour as above, a combination of a fully elastic zone and an elasto-plastic zone in which large-scale yielding is taking place is not sufficient. Jardine (1992) proposed to divide the stress space into zones where a geomaterial exhibits apparently different stress-strain behaviours, as presented on the inviscid principal stress plane in Fig. 3. This framework, which is originally rate- and time-independent, is used hereafter to develop a model that can describe the effects of viscous property and ageing on the stress-strain behaviour, in particular yielding characteristics.

Figure 3(a) shows different zones when the current total and inviscid stress states are at point $O$ (stationary state) and therefore yielding is not taking place. According to Jardine (1992), the two internal zones are kinematic with their locations depending on the position of the considered initial stress point (point $O$ in Fig. 3(a)), as well as loading history. With an elasto-viscoplastic geomaterial, the total stress state reaches point $O$ after the viscous stress component has disappeared, for example, by creep deformation or stress relaxation for some long period. As long as the shear strain increment by mono-
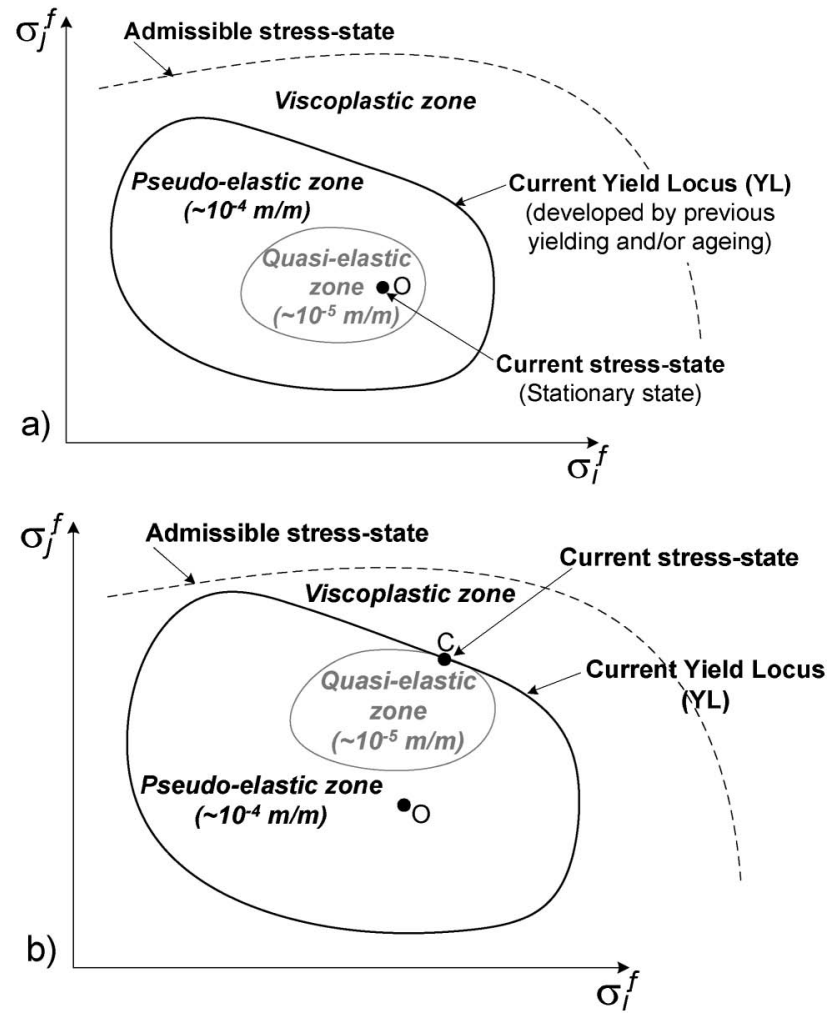

Fig. 3. Rheological characteristic zones on the inviscid principal stress plane when the current inviscid stress state is at: (a) point $O$ (stationary and unyielding) and (b) point $C$ (during yielding)

tonic loading along a fixed stress path starting from point $C$ does not exceed some $10^{-5} \mathrm{~m} / \mathrm{m}$, the inviscid stress state remains inside the quasi-elastic zone and the stressstrain behaviour is highly reversible and linear exhibiting the maximum tangent stiffness. This quasi-elastic behaviour of unbound and bound geomaterials was studied and characterized by a great number of researchers (e.g., Hardin and Blandford, 1989; Burland, 1989; Tatsuoka and Shibuya, 1991; among many others). As the strain becomes larger, the inviscid stress state may leave the quasi-elastic zone and enter the pseudo-elastic zone. As long as the inviscid stress state remains inside this latter zone, the tangent stiffness is still high, whereas a hysteretic phenomenon showing the start of small energy dissipation and irreversible deformation appears. The pseudoelastic behaviour is the transitional behaviour between the quasi-elastic behaviour (showing essentially recoverable strains and highly linear stress-strain relation) and the noticeably visco-plastic behaviour (showing primarily irreversible strains associated with large scale yielding). With Magnus till clay, the size of this zone in terms of strain is about $10^{-4} \mathrm{~m} / \mathrm{m}$ (Jardine, 2002). Similar values with cement-mixed gravelly soils are reported in this paper (i.e., some $10^{-4} \mathrm{~m} / \mathrm{m}$ for axial strain during monotonic loading along a fixed loading path). In the last zone, called the viscoplastic zone, large-scale yielding takes place associated with the development of large and essentially irreversible strain increments. The boundary between the pseudo-elastic zone and the viscoplastic zone is 
defined as the yield locus for large-scale yielding, or simply the yield locus (YL), in this study. When the current inviscid stress point is located on YL (point $C$ in Fig. $3(\mathrm{~b})$ ), the locations of the quasi-elastic and pseudo-elastic zones have either expanded by isotropic hardening or moved by kinematic hardening. Accurate evaluation of the location of current YL (Fig. 3) is particularly important when evaluating the deformation of ground and soil structure. As long as the inviscid stress state remains inside the pseudo-elastic zone for a given loading history, strain increments are kept rather small, which may be nearly reversible. With young cement-mixed soil, this preferred situation becomes more likely, as YL expands with time by continuing positive ageing effects, as well as strain-hardening associated with creep deformation, as illustrated in the next section.

Development of Yield Locus When Subjected to Ageing

When the stress variable is single, as in the case of drained TC at a fixed confining pressure, $\sigma_{\mathrm{h}}^{\prime}=\sigma_{3}^{\prime}$, the deviator stress, $q=\sigma_{\mathrm{v}}^{\prime}-\sigma_{\mathrm{h}}^{\prime}=\sigma_{1}^{\prime}-\sigma_{3}^{\prime}$, when large-scale yielding starts (called the yield deviator stress) becomes larger as either strain-hardening associated with inviscid yielding or ageing effects or both take place. The experimental data showing the above are shown later in this paper (i.e., Fig. 6 and others). Corresponding to the above, the yield locus (YL) on the inviscid stress plane and the yield surface in the inviscid stress space expand. According to the modified three-component model de- scribed in Figs. 1 and 2, ageing directly affects the inviscid yielding characteristics of $\mathrm{P}$ body as illustrated below.

In Fig. 4 , point $B$ represents the current total stress state $\left(\sigma=\sigma^{\mathrm{f}}+\sigma^{v}\right)$. Point $F$ represents the current inviscid stress state $\left(\underline{\sigma}^{\mathrm{f}}\right)$. The inviscid yielding is defined by the development of $d \sigma^{\mathrm{f}}: n\left(S^{\mathrm{f}}\right) \geq 0$ ( $n$ is the normal to the yield surface $S^{\mathrm{f}}$ ), which takes place if the following conditions are satisfied:

$$
\begin{aligned}
& {\left[S^{\mathrm{f}}\right]_{(\tau, \mathrm{t})}=\left[S_{\mathrm{y}}^{\mathrm{f}}\right]_{(\tau, \mathrm{t})}} \\
& {\left[d S^{\mathrm{f}}\right]_{(\tau, \mathrm{t})}=\left[d S_{\mathrm{y}}^{\mathrm{f}}\right]_{(\tau, \mathrm{t})}}
\end{aligned}
$$

where $S_{\mathrm{y}}^{\mathrm{f}}\left(\sigma_{\mathrm{y}}^{\mathrm{f}}\right)$ represents the inviscid YL, along which the inviscid stress $\left(\sigma^{\mathrm{f}}\right)$ is equal to the inviscid yield stress $\underline{\sigma}_{\mathrm{y}}^{\mathrm{f}}$ (NB: $S_{\mathrm{y}}\left(\sigma_{\mathrm{y}}\right)$ represents the current YL in terms of total stresses, along which the stress $(\sigma)$ is equal to the yield stress, $\sigma_{\mathrm{y}} . S_{\mathrm{y}}\left(\sigma_{\mathrm{y}}\right)$ may or may not have the same functional form as $S_{\mathrm{y}}^{\mathrm{f}}\left(\sigma_{\mathrm{y}}^{\mathrm{f}}\right)$ depending on applied loading stress paths. $\left[S_{\mathrm{y}}^{\mathrm{f}}\right]_{(\tau, \mathrm{t})}$ is the inviscid yield surface of $\mathrm{P}$ body when "instantaneous $\underline{\varepsilon}^{\mathrm{ir}}$ " is equal to $\tau$ and "the instantaneous ageing period (with a fixed origin defined at the start of ageing) $t_{\mathrm{c}}$ " is equal to $t .\left[S^{\mathrm{f}}\right]_{(\tau, t)}$ represents the inviscid stress states when $\varepsilon^{\mathrm{ir}}=\tau$ and $t_{\mathrm{c}}=t$, on which the stress state at point $F$ is located. $S^{\mathrm{f}}\left(\sigma^{\mathrm{f}}\right)$ is assumed to have the same functional form as $S_{\mathrm{y}}^{\mathrm{f}}\left(\sigma_{\mathrm{y}}^{\mathrm{f}}\right)$. $\left[d S^{\mathrm{f}}\right]_{(\tau, \mathrm{t})}$ and $\left[d S_{\mathrm{y}}^{\mathrm{f}}\right]_{(\tau, \mathrm{t})}$ are the increments of $\left[S^{\mathrm{f}}\right]_{(\tau, \mathrm{t})}$ and $\left[S_{\mathrm{y}}^{\mathrm{f}}\right]_{(\tau, \mathrm{t})}$.

Figures 4(a)-(d) explain the structure of Eqs. (7a) and (7b) when the viscous property is the Isotach type, which is most classical and most straightforward among the different viscous property types that have been found


Fig. 4. Current stress states and yield loci under different yielding and loading conditions: (a) yielding; (b) non-yielding with $\underline{\underline{d \sigma}}=\underline{\underline{0}}$; (c) non-yielding with $\underline{d \sigma^{\mathrm{f}}}: \underline{\underline{n}}\left(S^{\mathrm{f}}\right) \geq 0$; and (d) restart of yielding (in the case of Isotach viscosity) 


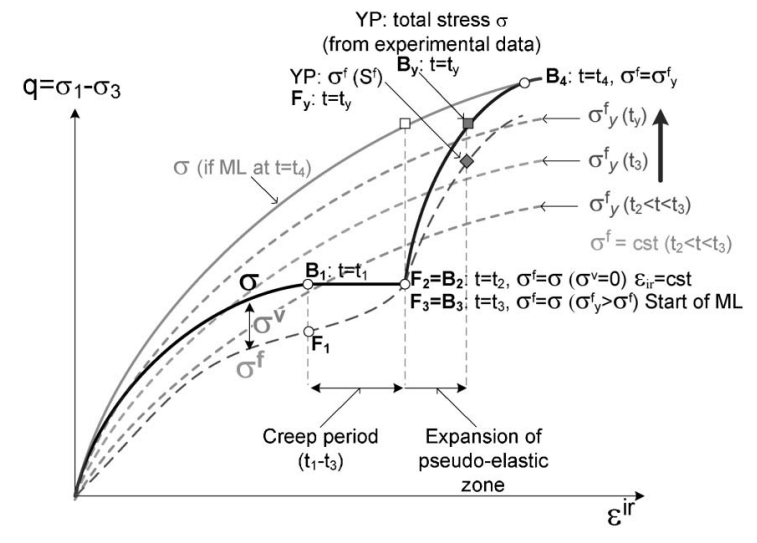

Fig. 5. Typical stress-strain response corresponding to the loading history illustrated in Fig. 4 (i.e., yielding during ML, non-yielding during creep with ageing, expansion of pseudo-elastic zone, and finally restart of large-scale yielding) in the case without interaction effects between yielding and ageing

with geomaterials (Tatsuoka et al., 2008a). In this case, under continuous monotonic loading (ML) conditions along a fixed stress path with a single stress variable (e.g., $\mathrm{TC}$ at a fixed confining pressure), the increment of viscous stress $\left(\sigma^{\mathrm{v}}\right), \Delta \sigma^{\mathrm{v}}$, that develops at a given moment by an irreversible strain increment, $\Delta \varepsilon^{\text {ir }}$, or an irreversible strain rate increment, $\Delta \dot{\varepsilon}^{\text {ir }}$, or both does not decay with an increase in $\varepsilon^{\text {ir }}$ during subsequent loading. So, the current $\sigma^{\mathrm{v}}$ is a function of instantaneous $\varepsilon^{\text {ir }}$ and its rate, $\dot{\varepsilon}^{\text {ir }}$ and the strength during ML at a constant $\dot{\varepsilon}$ increases with $\dot{\varepsilon}$. Figure 5 illustrates typical stress-strain relation during TC loading at a fixed confining pressure corresponding to the loading history illustrated in Fig. 4. With the other three viscous property types, $\Delta \sigma^{\mathrm{v}}$ that develops at a given moment decays towards different residual values with an increase in $\varepsilon^{\text {ir }}$ during subsequent loading (Tatsuoka et al., 2008a).

Figures 4(a) and (b) illustrate the inviscid yielding process (where $\underline{\underline{d \sigma^{\mathrm{f}}}}: \underline{\underline{n}}\left(S^{\mathrm{f}}\right) \geq 0$ ) when the $\underline{\underline{\sigma}}^{\mathrm{f}}$ state moves from $F_{1}$ to $F_{2}$ (located outside $\left(S^{\mathrm{f}}\right)_{1}$, shown in Fig. 4(b)). In this illustrative case, no interaction effect between inviscid yielding and ageing is introduced: i.e., the $\sigma^{\mathrm{f}}-\varepsilon^{\mathrm{ir}}$ relation for a given $t_{\mathrm{c}}$ is unique, independent of loading history (Tatsuoka et al., 2008b). In Fig. 4(b), inviscid yielding stops and $\underline{\sigma}^{\mathrm{v}}$ becomes zero when stage 2 is reached: i.e., when the $\sigma^{\text {f }}$ state has reached $F_{2}$ at the end of creep deformation. This is the moment when the irreversible strain rate has become zero and the inviscid and current stress states have become the same (i.e., $F_{2}=B_{2}$ ) for the first time since the start of loading. Subsequently, a non-yielding process starts where $\underline{\sigma}=\underline{\sigma}^{\mathrm{f}}$ under the condition of $d \sigma=0$. During the non-yielding process, $d \varepsilon^{\mathrm{ir}}=0$,


as the relation: $\overline{\bar{d}} \underline{\underline{\sigma}}=d \underline{\underline{\sigma^{\mathrm{f}}}}+d{\underline{\underline{\sigma^{\mathrm{v}}}}}^{\mathrm{v}}$ should be always valid, we have:

$$
\left[d \underline{\underline{\sigma}}^{\mathrm{f}}\right]_{(\mathrm{t}, \tau)}=[d \underline{\underline{\sigma}}]_{(\mathrm{t}, \tau)}
$$

where $[d \sigma]_{(t, \tau)}$ is a given total stress increment. Then, we have $d{\underline{\underline{\sigma^{f}}}}^{\underline{\underline{\sigma}}}=\underline{\underline{0}}$. That is, both $\underline{\underline{\sigma}}^{\mathrm{f}}$ and $\underline{\underline{\sigma}}$ states do not move staying at point $F_{2}=F_{3}\left(=B_{2}=B_{3}\right)$. Even during this nonyielding process, $S_{\mathrm{y}}^{\mathrm{f}}$ develops with time by positive ageing effects as $\left(S_{\mathrm{y}}^{\mathrm{f}}\right)_{2} \rightarrow\left(S_{\mathrm{y}}^{\mathrm{f}}\right)_{3}$ (n.b., in the case of negative yielding, which is not dealt with in this paper, $S_{\mathrm{y}}^{\mathrm{f}}$ shrinks with time; Tatsuoka et al., 2003). This process appears typically with young cement-mixed soil at later stages of sustained loading at a fixed stress state (as explained later, related to Fig. 15). In Fig. 4(c), $\underline{\underline{\sigma}}^{\mathrm{f}}$ and $\underline{\underline{\sigma}}$ states move from point $F_{3}\left(=B_{3}\right)$ to different points $F_{\mathrm{a}}$ and $B_{\mathrm{a}}$ still under non-large-scale yielding conditions. During this process, the current inviscid stress state remains inside the pseudo-elastic zone $\left(S_{\mathrm{y}}^{\mathrm{f}}\right)$ that has developed by inviscid yielding and ageing. Therefore, not only elastic strain increments but also small visco-plastic strain increments develop while the major part of strain increments is elastic. This behaviour makes the locations of $F_{\mathrm{a}}$ and $B_{\mathrm{a}}$ slightly different due to the development of small viscous stress component. During this process, $S_{\mathrm{y}}^{\mathrm{f}}$ develops with time as $\left(S_{\mathrm{y}}^{\mathrm{f}}\right)_{3} \rightarrow\left(S_{\mathrm{y}}^{\mathrm{f}}\right)_{\mathrm{a}}$ by positive ageing effects. In Fig. 4(d), $\left[S^{\mathrm{f}}\right]_{(\tau, \mathrm{t})}$ catches up with $\left[S_{\mathrm{y}}^{\mathrm{f}}\right]_{(\tau, \mathrm{t})}$ as $\underline{\underline{\sigma}}^{\mathrm{f}}$ and $\underline{\underline{\sigma}}$ states move from the common point $F_{3}\left(=B_{3}\right)$ to different points $F_{\mathrm{y}}$ and $B_{\mathrm{y}}$. Large-scale yielding restarts taking place in $\mathrm{P}$ body (Fig. 1(a)) as $\underline{\underline{\sigma}}^{\mathrm{f}}$ state moves from point $F_{\mathrm{y}}$ to point $F_{4}$ while $\underline{\underline{\sigma}}$ state moves from point $B_{\mathrm{y}}$ to point $B_{4}$. At this stage, the major part of strain increments becomes viscoplastic. It may readily be seen from the arguments above that the relevant formulation of inviscid YL is crucial to apply the proposed model to general stress conditions.

\section{Determination of Yield Point}

The yield surface in the inviscid stress space (i.e., the yield locus on the inviscid stress plane) is the boundary between the pseudo-elastic zone and the visco-plastic zone with large-scale yielding. In the present study, yield points (YPs) were experimentally determined as follows to locate yield loci (YLs) on the $\left(p^{\prime}, q\right)$ plane (i.e., on the total stress plane). As discussed later in this paper, the yield loci on the inviscid stress plane, $S_{\mathrm{y}}^{\mathrm{f}}$ can be inferred from these yield loci determined in terms of measured stresses (i.e., total stresses).

Figure 6 shows three drained TC tests typical of those performed in the present study. The test conditions are reported later in this paper. One of the three tests included two-day re-curing by SL at a fixed stress state. Along the measured stress-strain curve observed upon the restart of ML at the end of SL, it was firstly attempted to define a yield point (YP) at a point where the following two sub-relations intersect: 1) the elastic relation inferred from the initial part of stress-strain curve immediately after the restart of ML (i.e., the quasi-elastic behaviour); and 2) the continuous ML relation in the case without intermediate re-curing, inferred from the curve after the restart of large-scale yielding while referring to the curve from a consistently continuous ML test for the same total curing time (i.e., nine days in this case). In Fig. 6(a), a solid circle denotes the YP determined by this graphical method. Another method, based on numerical analysis shown in Fig. 6(b), was then attempted: i.e., the point of maximum curvature (i.e., minimum curvature radius) 



Fig. 6. Two methods to determine $\mathrm{YP}$ in terms of total stresses during ML: (a) three drained TC tests at $\sigma_{\mathrm{h}}^{\prime}=20 \mathrm{kPa}$ with and without re-curing for two days at $q=1,000 \mathrm{kPa}$ and (b) plot of curvature radius versus strain relation of the curve fitted to the stress-strain curve measured after twoday re-curing (plotted in full-log)

was obtained along the $\log$ (stress) versus $\log$ (strain) curve fitted to the stress-strain curve measured upon the restart of ML after two-day re-curing. A solid square shown in Fig. 6(a) denotes the YP obtained by this more objective procedure. This method has such an advantage that results are free from the units used for the two coordinates and has been widely used in geotechnical engineering practice (e.g., the determination of pile bearing capacity from pile load and settlement relations from pile loading tests). The YP in terms of total stress determined by this method is also presented in Fig. 7. In the test described in Fig. 7, YP was determined along the stress path where $q$ was kept constant. If the rheological behaviour of a material suddenly changes from purely elastic behaviour to elasto-plastic one, the YPs obtained by the two methods should become the same. In fact, the yield stresses determined by these two methods are very similar for the data obtained for two different stress paths presented in Figs. 6 and 7. However, the graphical method becomes more subjective when the confining pressure is changed largely from the value during two-day re-curing to higher pressure during the determination of YP. It is also the case where rather complex stress paths are applied after re-curing. Therefore, the numerical procedure, which is more objective, was employed to determine YPs in all the tests presented in this paper.

Each YL is determined by connecting multiple YPs obtained for the same curing history (i.e., the same re-curing stress state for the same period at the same total curing period), as explained in detail in the next section. It may be seen from Fig. 7(b) that the YP obtained from ML that continued at $q=$ constant (i.e., a data point indicated by a cross circle in Fig. 21(b)) is located on the YL determined by performing classical triaxial compression tests (i.e., $\sigma_{v}^{\prime}$ was increasing at constant $\sigma_{\mathrm{h}}^{\prime}$ ). This fact indicates that the respective yield loci are essentially independent of the stress path followed inside the pseudoelastic zone.

As illustrated in Fig. 8(a), three types of secant Young's modulus, $E_{\mathrm{sec}}=\Delta q / \Delta \varepsilon_{\mathrm{v}}$, were obtained from the deviator stress and axial strain relations observed until
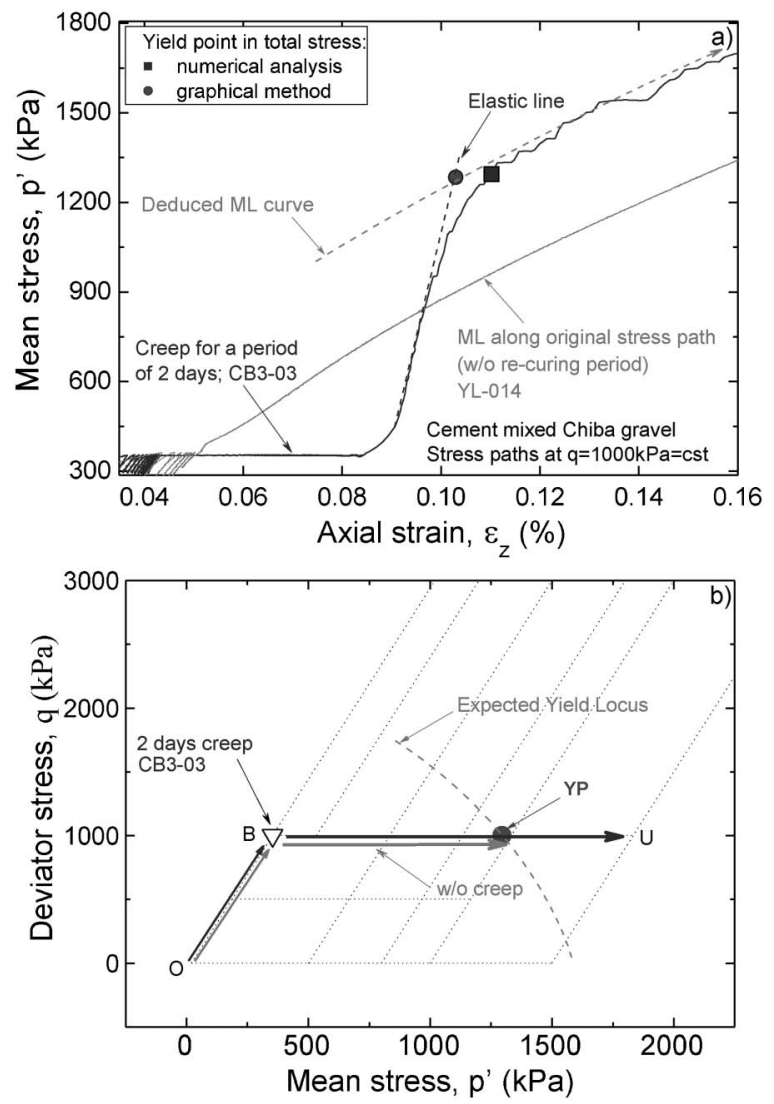

Fig. 7. Two methods to determine YP during ML increasing $p^{\prime}$ at $q=$ $1,000 \mathrm{kPa}$ : (a) two tests with and without re-curing for two days and (b) stress paths and YP (at nearly the same $p^{\prime}$ by the two methods)

the stress state reached the outer boundary of the pseudoelastic zone in terms of total stresses obtained by a number of TC tests on cement-mixed model Chiba gravel. In one test, monotonic loading was continued after initial curing for 9 days, in which an YP was obtained (i.e., a point denoted by the symbol + in Fig. 8(a)). The data point denoted by the symbol + in Fig. $8(\mathrm{~b})$ indicates the secant Young's modulus $E_{\text {sec }}(0)$ obtained from this test. 
In the other tests, after two day re-curing during otherwise primary loading at different confining pressures on specimens initially cured for 7 days, an YP was determined during ML that was restarted at the confining pressure that was either kept the same or changed. The $E_{\text {sec }}$ values from all the tests in which the primary ML was performed at confining pressure equal to $20 \mathrm{kPa}$ were obtained from the relationships between the values of $\Delta q$ and $\Delta \varepsilon_{\mathrm{v}}$ presented in Fig. 8(b). The following trends of behaviour may be seen from this figure:

1) The relation appears to be rather unique, exhibiting a rather unique secant Young' modulus, for the three different loading histories for a given total curing time $t_{\mathrm{c}}$. This fact indicates that the numerical method to determine YPs, described above, is relevant.

2) The average slope of the relation indicates the average secant Young's modulus $E_{\text {sec }}$ (in terms of total stress and strain increments), which is equal to $3.3 \mathrm{GPa}$. Due to the inclusion of inelastic component in the $\Delta \varepsilon_{\mathrm{v}}$ value by which the $E_{\text {sec }}$ value was determined, this modulus is about a half of the elastic Young modulus $E_{\mathrm{z}}$, equal to $6 \mathrm{GPa}$, evaluated by applying small unload/reload cycles under similar conditions after a total curing period of 9 days (Kongsukprasert and Tatsuoka, 2007; Tatsuoka et al., 2008b). This fact

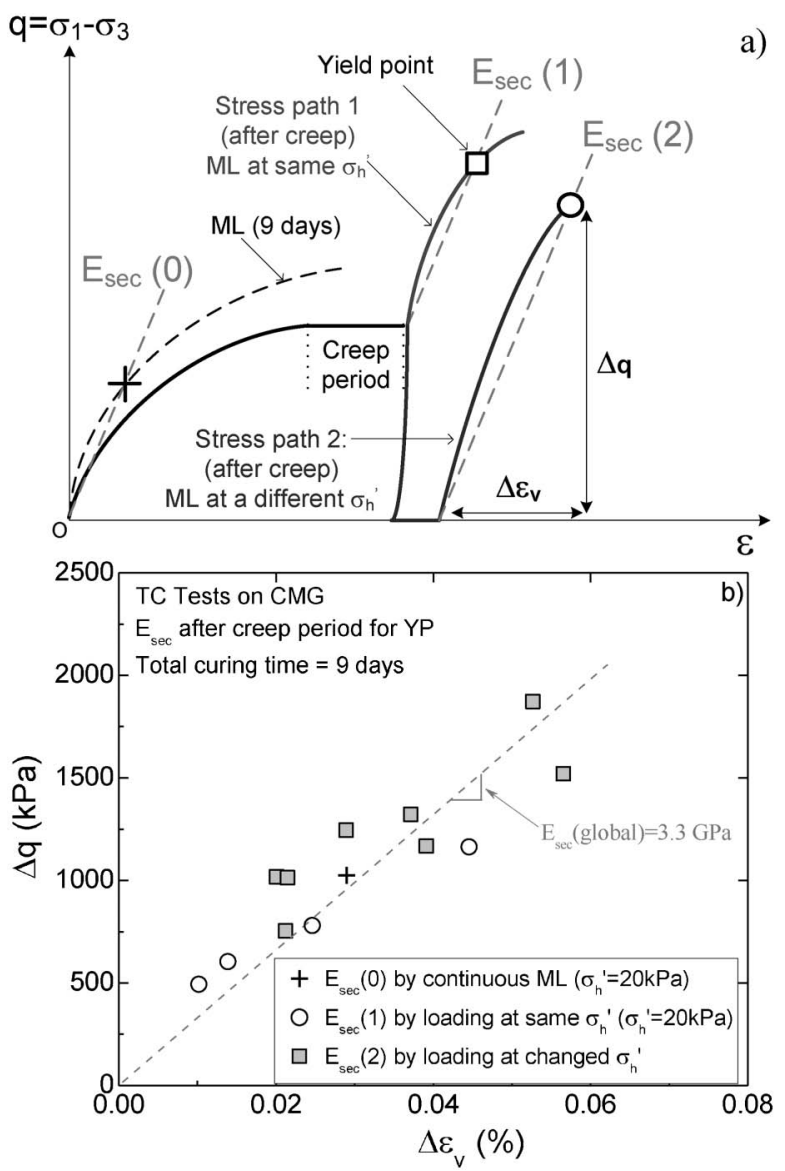

Fig. 8. Secant modulus $E_{\text {sec }}$ in the pseudo-elastic zone (inside the YL): (a) definition of $E_{\text {sec }}$ for different stress paths after re-curing and (b) $\Delta q$ (deviator stress) versus $\Delta \varepsilon_{\mathrm{v}}$ (vertical strain) relations, showing different $E_{\text {sec }}$ values defined in Fig. 8(a)

confirms that the pseudo-elastic zone should be defined different from the quasi-elastic zone in the tests performed in the present study. It is to be noted that both $E_{\text {sec }}$ and $E_{\mathrm{z}}$ values increase with an increase in the total curing time $t_{\mathrm{c}}$.

The two remarks with respect to the location of $\mathrm{YL}$ shown above (i.e., independency of stress paths inside the pseudo-elastic zone and a rather unique stiffness for stress-strain relations before reaching the outer boundary of the pseudo-elastic zone when re-cured in the same way) indicate that we can define yield loci in an objective way and then analyze the effects of continuous yielding and ageing on its development, as discussed in the next sections.

\section{TEST METHODS}

\section{Test Materials}

Figure 9 shows the grading curves and particle pictures of the two granular materials (GMs) used in the present study. The first one is an angular crushed sandstone (called model Chiba gravel, the same type as used by Kongsukprasert and Tatsuoka, 2005), made by sieving the original one from a quarry. The other is a crushed concrete aggregate (called REPA, the same type as used by Aqil et al., 2005; Tatsuoka et al., 2006), made by sieving the one produced by crushing steel-reinforced concrete electricity poles to have a similar grading as model Chiba gravel. A maximum particle size equal to $10 \mathrm{~mm}$ was selected as only relatively small specimens can be accommodated in a high pressure triaxial cell used in the

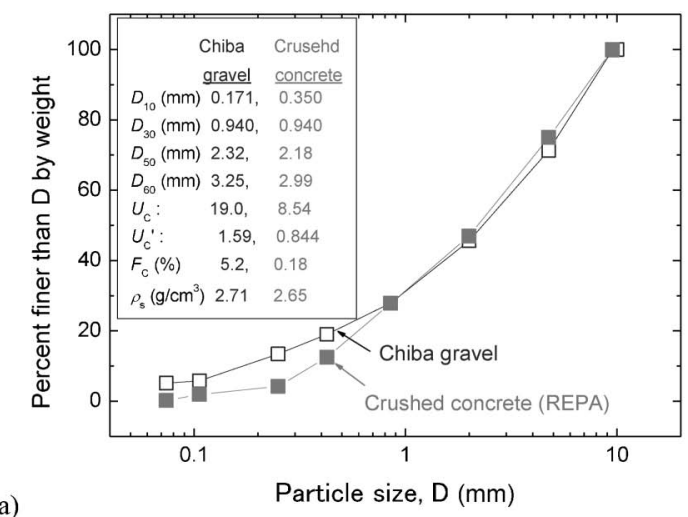



Sieved Chiba gravel

b)

Fig. 9. (a) Grading curves of two tested materials and (b) pictures of particles

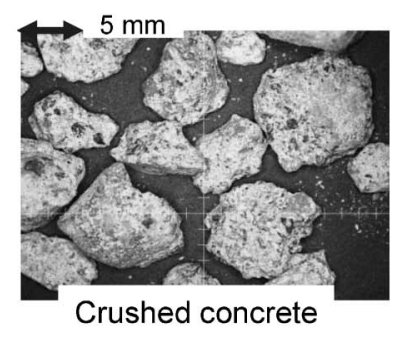

Crushed concrete 

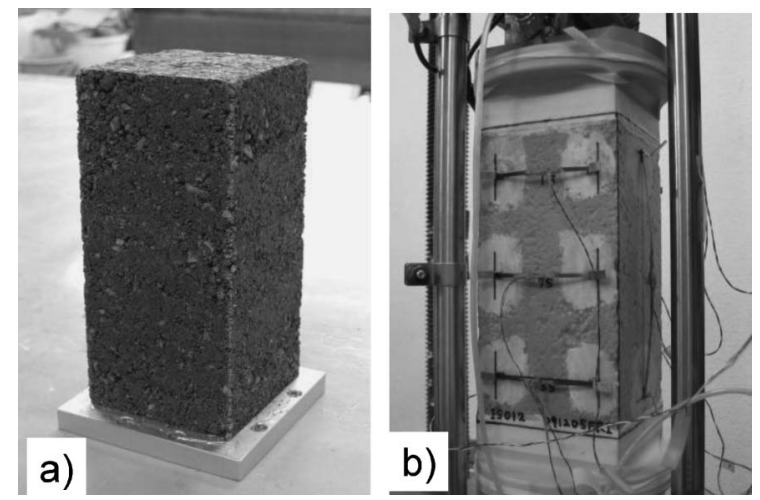

Fig. 10. Specimen: (a) immediately before setting in the triaxial cell and (b) with a rubber membrane standing by partial vacuum

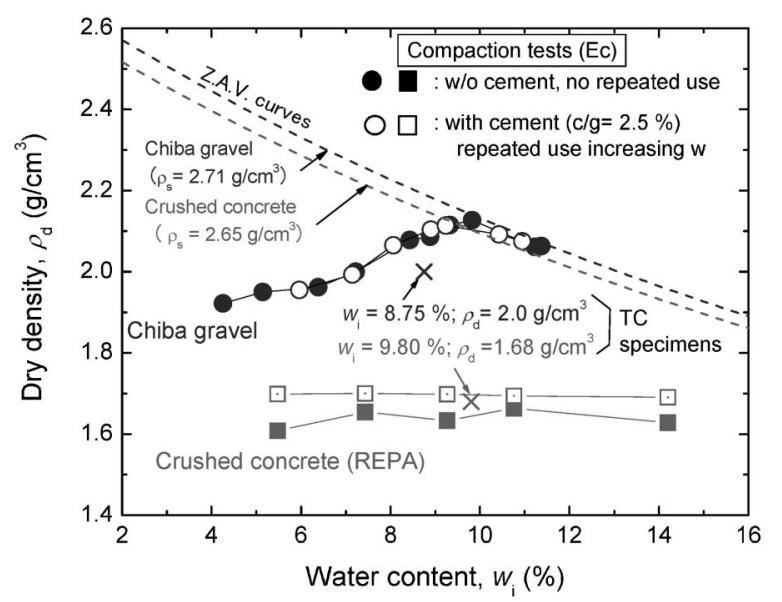

Fig. 11. Compaction curves of two granular materials with and without cement-mixing

present study. Rectangular prismatic specimens of $72 \mathrm{~mm}$ $\times 72 \mathrm{~mm}$ in cross-section times $150 \mathrm{~mm}$ high (Fig. 10) were used.

The crushed concrete aggregate consists of coarse relatively angular stiff core particles covered with a thin layer of mortar. For this reason, the average particle density, $\rho_{\mathrm{s}}$ is slightly smaller than model Chiba gravel. This material was used in the present study to examine whether crushed concrete aggregate and its cement-mixture can be used as high-quality backfill materials, like selected high-quality natural gravelly soils (e.g., model Chiba gravel) and their cement-mixtures, to construct permanent important civil engineering structures allowing a limited amount of instantaneous and residual deformation (such as bridge abutments) (Aqil et al., 2005; Tatsuoka, 2004; Tatsuoka et al., 2006). Figure 11 shows the compaction curves of the two materials and their mixtures with normal Portland cement (cement/gravel $=2.5 \%$ by weight) obtained by compaction using the same compaction energy (i.e., $550 \mathrm{~kJ} / \mathrm{m}^{3}$; the standard Proctor) performed right after adding water to the mixture. The effects of cement-mixing on the compaction curve are negligible with model Chiba gravel, while the compacted density of crushed concrete increases slightly by cement-mixing. Horpibul- suk et al. (2006) reported a different trend of behaviour from their experiment. Further study will be necessary to find the reasons for this variance. The dry density of the crushed concrete aggregate achieved by using the same compaction energy is much smaller than model Chiba gravel, which is due likely to its specific particle constitution that makes smooth packing of particles difficult. Furthermore, the compaction curve of the crushed concrete aggregate is much flatter. It seems that these trends of behaviour are due to a more angular shape and a rougher surface of particles of the crushed concrete aggregate (Fig. 9(b)). However, the details are not known. Despite largely different compaction curves, when compared for the same degree of compaction (defined as the ratio of compacted dry density to the maximum dry density), the drained TC compressive strength of the crushed concrete aggregate is very similar to that of model Chiba gravel for a wide range of confining pressure (Aqil et al., 2005; Tatsuoka et al., 2006). It is also shown in this paper that the drained TC strengths of cement-mixed specimens of these two different GMs compacted similarly dense relative to the respective maximum dry densities are similar.

The specimens (Fig. 10) were produced by tamping moist cement-mixed gravelly soil. The compacted conditions are denoted by the symbol $x$ in Fig. 11. The dry density and water content when compacted of cementmixed model Chiba gravel were made identical to those in the previous studies (Kongsukprasert and Tatsuoka, 2005; Kongsukprasert et al., 2007; Tatsuoka et al., 2008 b) so that the results from the present study can be analysed by referring to a large data base from these previous studies. The compaction energy level used to prepare the specimens of the two types cement-mixed gravelly soil is slightly smaller than the standard Proctor $(1 \mathrm{Ec})$ and it is rather representative of the one encountered in construction projects using a relatively small compactor, such as construction of the backfill in a narrow area (e.g., behind a bridge abutment). The compaction energy level in construction projects using a relatively large compactor could be higher (e.g., 4.5Ec). The specimens were removed from the mold five days after compaction and then sealed for further curing at constant water content under the atmospheric pressure.

The vertical (axial) and horizontal (lateral) strains, $\varepsilon_{\mathrm{v}}$ and $\varepsilon_{\mathrm{h}}$, were measured locally by means of a pair of vertical local deformation transducers (LDTs) arranged on two opposite lateral faces and three pairs of horizontal LDTs arranged on the other two opposite lateral faces (Fig. 10(b)). A high pressure triaxial cell with a cell pressure capacity of $3 \mathrm{MPa}$ was used. To minimize inhomogeneous deformation and associated non-uniform stress distribution within the specimen due to bedding errors and high friction, the top and bottom of the specimen were made smooth by pasting a thin layer of gypsum mixed with water and, after it solidified, lubricated by smearing a thin layer of silicon grease. Thrust force that may be induced by non-symmetric deformation due to shear banding in the specimen may damage the apparatus (in particular a load cell fixed between the specimen cap 



Fig. 12. (a) Stress paths until and after re-curing at points $B$ to $E$ and (b) stress paths followed after re-curing at point $B$ (for cement-mixed model Chiba gravel)

and the loading piston). To alleviate the above, the specimen pedestal was placed on a bearing system that allows free lateral displacements in any direction. More details of the testing method are described in Hayano et al. (1997, 2001).

\section{Triaxial Compression Loading}

Figures 12(a) and (b) show the stress paths used to evaluate the effects of initial curing and re-curing at a certain stress-state on the location and shape of YL in terms of measured total stress (i.e., $\sigma$ in Fig. 1), along which the $\sigma_{\mathrm{h}}^{\prime}$ value is higher or lower than, or the same as, the value during re-curing. The specimens, moist as compacted, were initially cured under unstressed conditions (point 1) for 7 days or 9 days depending on the subsequent loading history and then brought to stress point $O$ $\left(q=0 ; \sigma_{\mathrm{h}}^{\prime}=19.8 \mathrm{kPa} \approx 20 \mathrm{kPa}\right)$. Subsequently, the following different TC loading histories were applied:

a) $\sigma_{\mathrm{h}}^{\prime}$ was kept the same or increased after re-curing (Fig.

12(a); both materials): Drained monotonic loading (ML) TC at $\sigma_{\mathrm{h}}^{\prime}=20 \mathrm{kPa}$ and $\dot{\varepsilon}_{\mathrm{v}}=0.03 \% / \mathrm{min}$ was started from point $O$ and ended at point $B(q=1.0$ $\left.\mathrm{MPa} ; \sigma_{\mathrm{h}}^{\prime}=20 \mathrm{kPa}\right)$, where the specimens were re-cured for two days. Then, ML was restarted at $\dot{\varepsilon}_{\mathrm{v}}=0.03 \%$ $/ \mathrm{min}$ (except for one test at $0.3 \% / \mathrm{min}$ described in Fig. 13) toward ultimate failure either at the same $\sigma_{\mathrm{h}}^{\prime}$ $(=20 \mathrm{kPa})$, or after $\sigma_{\mathrm{h}}^{\prime}$ was increased to $0.2 \mathrm{MPa}$ (point $K$ ) or $0.8 \mathrm{MPa}$ (point $L$ ), $1.0 \mathrm{MPa}$ (point $S$ ) and 1.5 MPa (point $T$ ) via different stress paths. The stress paths followed after re-curing at point $B$ are presented in Fig. 12(b). Only with cement-mixed model Chiba gravel, ML $\left(\sigma_{\mathrm{h}}^{\prime}=20 \mathrm{kPa}\right.$ and $\dot{\varepsilon}_{\mathrm{v}}=0.03 \%$ $/ \mathrm{min}$ ) started from point $O$ and ended also at point $C$ $\left(q=1.4 \mathrm{MPa} ; \sigma_{\mathrm{h}}^{\prime}=20 \mathrm{kPa}\right)$, located closer to the failure envelop. After re-curing for two days at point $C$, ML was restarted at $\dot{\varepsilon}_{\mathrm{v}}=0.03 \% / \mathrm{min}$ toward ultimate failure either at the same $\sigma_{\mathrm{h}}^{\prime}(=20 \mathrm{kPa})$, or after $\sigma_{\mathrm{h}}^{\prime}$ was increased to $0.5 \mathrm{MPa}$ (point $P$ ), $1.0 \mathrm{MPa}$ (point $S$ ) and $1.5 \mathrm{MPa}$ (point $T$ ) via different stress paths.

b) $\sigma_{\mathrm{h}}^{\prime}$ was kept the same or decreased after re-curing at the same stress point (Fig. 12(a); both materials): At stress point $E\left(q=1.0 \mathrm{MPa} ; \sigma_{\mathrm{h}}^{\prime}=1.0 \mathrm{MPa}\right)$, reached via different stress paths (i.e., $O \rightarrow B \rightarrow E$ and $O \rightarrow S \rightarrow E$ ), the specimens were re-cured for two days. Then, ML was restarted toward ultimate failure at $\dot{\varepsilon}_{\mathrm{v}}$ $=0.03 \% / \mathrm{min}$ either at the same $\sigma_{\mathrm{h}}^{\prime}(=1.0 \mathrm{MPa})$, or after $\sigma_{\mathrm{h}}^{\prime}$ was decreased to $0.5 \mathrm{MPa}$ (point $R$ ) or $20 \mathrm{kPa}$ (point $B$ ) via different stress paths.

c) $\sigma_{\mathrm{h}}^{\prime}$ was kept the same or decreased or increased after re-curing at the same stress point (Fig. 12(a); only cement-mixed model Chiba gravel): At stress point $D\left(q=0.5 \mathrm{MPa} ; \sigma_{\mathrm{h}}^{\prime}=1.0 \mathrm{MPa}\right)$, reached via different stress paths (i.e., $O \rightarrow A \rightarrow D$ and $O \rightarrow S \rightarrow D$ ), the specimens were re-cured for two days. Then, ML was restarted toward ultimate failure at $\dot{\varepsilon}_{\mathrm{v}}=0.03 \% / \mathrm{min}$ either at the same $\sigma_{\mathrm{h}}^{\prime}(=1.0 \mathrm{MPa})$, or after $\sigma_{\mathrm{h}}^{\prime}$ was either decreased to $20 \mathrm{kPa}$ (point $A$ ) or increased to $1.5 \mathrm{MPa}$ (point $T$ ).

In these tests, the total ageing time, $t_{\mathrm{c}}$, when ML was restarted toward ultimate failure was the same, 9 days, except for three tests performed to evaluate the effects of ageing period ( 7,8 or 14 days) in the case without performing re-curing. The stress paths in all these tests are summarized in Table 2. Five minute unload/reload cycles with a small vertical strain amplitude were applied occasionally to evaluate instantaneous elastic properties while confirming instantaneous strain-reversibility (or irreversibility).

The high-stiffness stress range (i.e., the pseudo-elastic range) becomes larger with an increase in the irreversible strain rate during ML during which a yield point appears, as seen from Fig. 13. To keep this viscous effect during ML identical, the same axial strain rate, $\dot{\varepsilon}_{\mathrm{v}}=0.03 \% / \mathrm{min}$, was employed during all the ML TC tests. Then, by assuming the same viscous effect in all the data, the yielding property in terms of inviscid stress of $\mathrm{P}$ component (Figs. 1 and 2) can be rather accurately estimated from the one in terms of measured total stresses reported in this paper. A period of two days for re-curing was arbitrarily chosen so that this study becomes feasible for a limited available period of time. To estimate more confidently the yield characteristics under field loading conditions, experiment with longer initial and re-curing periods will be necessary. 
Table 2. CD TC test conditions

\begin{tabular}{|c|c|c|c|c|c|c|c|c|}
\hline Test & $\begin{array}{l}w_{\mathrm{i}} \\
(\%)\end{array}$ & $\begin{array}{c}\rho_{\mathrm{d}} \\
\left(\mathrm{g} / \mathrm{cm}^{3}\right)\end{array}$ & Material & $\begin{array}{l}\text { Initial curing } \\
\text { period, } t_{\text {ini }}(\text { day) }\end{array}$ & $\begin{array}{c}\text { Total curing } \\
\operatorname{period}^{(1)}, t_{\mathrm{c}} \text { (day) }\end{array}$ & $\begin{array}{l}\text { Re-curing stress } \\
\text { state }\left(q, \sigma_{\mathrm{h}}^{\prime}\right)\end{array}$ & $\begin{array}{c}q_{\max } \\
(\mathrm{kPa})\end{array}$ & $\begin{array}{c}\text { Stress path } \\
\text { (stress points, Fig. 12a) }\end{array}$ \\
\hline YL-007 & 8.747 & 2.000 & $\mathrm{cg}$ & 7 & 7 & l & 1839 & O-A-B-C-X \\
\hline CB3-02 & 9.598 & 1.980 & $\mathrm{cg}$ & 9 & 9 & / & 1939 & O-A-B-C-X \\
\hline CB3-06 & 10.261 & 1.947 & $\mathrm{cg}$ & 9 & 9 & / & 3319 & O-P-Q-R-Y \\
\hline CB3-08 & 8.903 & 1.978 & $\mathrm{cg}$ & 9 & 9 & I & 4156 & O-P-L-S-D-E-Z \\
\hline CB3-10 & 9.839 & 1.955 & $\mathrm{cg}$ & 9 & 9 & / & 5.850 & O-P-L-S-T-U-W \\
\hline YL-008 & 8.748 & 2.000 & $\mathrm{cg}$ & 7 & 8 & $(1000,20)$ & 1846 & O-A-B*-C-X \\
\hline YL-015 & 8.751 & 2.000 & $\mathrm{cg}$ & 7 & 9 & $(1000,20)$ & 1991 & O-A-B ${ }^{*}-\mathrm{C}-\mathrm{X}$ \\
\hline YL-016 & 8.750 & 2.000 & $\mathrm{cg}$ & 7 & 9 & $(1000,20)$ & 2605 & O-A-B*-K-M \\
\hline YL-019 & 8.747 & 2.000 & $\mathrm{cg}$ & 7 & 9 & $(1000,20)$ & 4411 & O-A-B*-O-P-L-N \\
\hline YL-021 & 8.749 & 2.000 & $\mathrm{cg}$ & 7 & 9 & $(1000,20)$ & 4749 & O-A-B*-O-S-E-Z \\
\hline CB3-03 & 8.904 & 1.989 & $\mathrm{cg}$ & 7 & 9 & $(1000,20)$ & 5239 & O-A-B*-K-R-E-U-W \\
\hline YL-022 & 8.748 & 2.000 & $\mathrm{cg}$ & 7 & 9 & $(1000,20)$ & 5900 & O-A-B*-O-L-T-U-W \\
\hline $\mathrm{H}-02$ & 8.038 & 1.983 & $\mathrm{cg}$ & 7 & 14 & $(1000,20)$ & 2477 & O-A-B*-C-X \\
\hline YL-033 & 9.040 & 1.970 & $\mathrm{cg}$ & 7 & 9 & $(1400,20)$ & 2157 & O-A-B-C*-X \\
\hline YL-034 & 8.030 & 1.970 & $\mathrm{cg}$ & 7 & 9 & $(1400,20)$ & 3579 & O-A-B-C*-O-P-R-Y \\
\hline YL-032 & 9.440 & 1.970 & $\mathrm{cg}$ & 7 & 9 & $(1400,20)$ & 4612 & O-A-B-C*-O-S-D-E-Z \\
\hline YL-031 & 9.330 & 1.980 & $\mathrm{cg}$ & 7 & 9 & $(500,1000)$ & 1856 & O-A-Q-D*-A-B-C-X \\
\hline CB3-05 & 9.546 & 1.982 & $\mathrm{cg}$ & 7 & 9 & $(500,1000)$ & 3542 & O-P-L-S-D*-Q-R-Y \\
\hline YL-028 & 9.530 & 1.970 & $\mathrm{cg}$ & 7 & 9 & $(500,1000)$ & 4540 & O-A-Q-D*-E-Z \\
\hline CB3-17 & 9.478 & 1.972 & $\mathrm{cg}$ & 7 & 9 & $(500,1000)$ & 5700 & O-P-L-S-D* ${ }^{*}$-S-T-U-W \\
\hline YL-026 & 8.750 & 1.980 & $\mathrm{cg}$ & 7 & 9 & $(1000,1000)$ & 2400 & O-A-B-K-R-E*-B-C-X \\
\hline YL-027 & 9.050 & 1.980 & $\operatorname{cg}$ & 7 & 9 & $(1000,1000)$ & 3453 & O-A-B-K-R-E*-R-Y \\
\hline YL-014 & 8.750 & 2.000 & $\mathrm{cg}$ & 7 & 9 & $(1000,1000)$ & 4400 & O-A-B-K-R-E*-Z \\
\hline CB3-04 & 9.740 & 1.962 & $\mathrm{cg}$ & 7 & 9 & $(1000,1000)$ & 5750 & O-P-S-D-E*-S-T-U-W \\
\hline c9 & 9.08 & 1.69 & $\mathrm{cc}$ & 7 & 9 & $(1000,20)$ & 1916 & $\mathrm{O}-\mathrm{A}-\mathrm{B}^{*}-\mathrm{C}-\mathrm{X}$ \\
\hline $\mathrm{c} 21$ & 9.95 & 1.65 & $\mathrm{cc}$ & 7 & 9 & $(1000,1000)$ & 1925 & O-A-B-K-R-E*-B-C-X \\
\hline $\mathrm{c} 15$ & 10.03 & 1.67 & $\mathrm{cc}$ & 7 & 9 & $(1000,20)$ & 3801 & O-A-B*-O-P-Y \\
\hline $\mathrm{c} 16$ & 10.01 & 1.68 & $\mathrm{cc}$ & 7 & 9 & $(1000,20)$ & 5703 & O-A-B*-O-P-S-Z \\
\hline $\mathrm{c} 24$ & 9.71 & 1.65 & $\mathrm{cc}$ & 7 & 9 & $(1000,1000)$ & 6021 & O-A-B-K-R-E*-Z \\
\hline $\mathrm{c} 23$ & 10.19 & 1.62 & $\mathrm{cc}$ & 7 & 9 & $(1000,1000)$ & 3852 & O-A-B-K-R-E*-R-Y \\
\hline
\end{tabular}

* Anisotropic stress-state where re-curing by sustained loading was performed

(1) $t_{\mathrm{c}}=$ initial curing at point (1) (unconfined); + re-curing period (sustained loading at an anisotropic stress-state) cg: Cement-Mixed Gravelly soil (model Chiba gravel)

cc: Crushed Concrete (mixed with cement)

\section{EFFECT OF AGEING}

Effects of Ageing on Subsequent Stress-strain Behaviour

Kongsukprasert and Tatsuoka (2005) and Tatsuoka et al. (2008b) observed significant ageing effects in drained $\mathrm{TC}$ tests at a fixed $\sigma_{\mathrm{h}}^{\prime}$ on compacted cement-mixed model Chiba gravel, as illustrated in Fig. 14. That is, the strength and stiffness is larger in test $b$ than in test $a$ due to longer ageing at zero deviator stress (i.e., $q=0$ ). In test $c$, the specimen is firstly aged at $q=0$ for the same period as test $a$, then re-cured by sustained loading (SL) at $q=$ $q_{\mathrm{SL}}(>0)$ until the total curing period became the same as test $b$. In test $c$, the specimen exhibits very high stiffness for a large stress range (i.e., the pseudo-elastic behaviour), which is much larger than the one when ageing effect is not activated. In Fig. 14, it is also illustrated that, for the same total curing period, the peak strength in test $c$ is larger than in test $b$. They considered that this additional strength gain is due to positive interaction between the ageing effect associated with an increase in the elapsed 


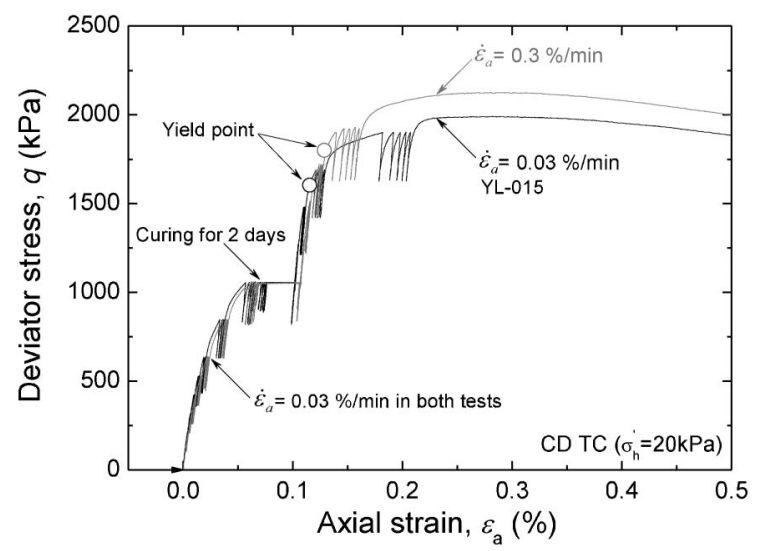

Fig. 13. Effects of strain rate on yield stress, cement-mixed model Chiba gravel (Tatsuoka et al., 2008b)

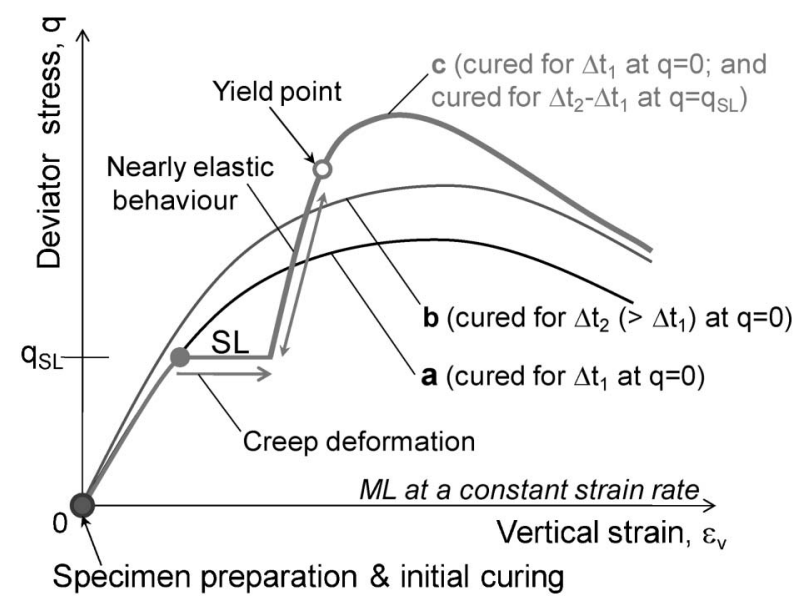

Fig. 14. Effects of curing in drained TC at a fixed $\sigma_{\mathrm{h}}^{\prime}$

time and the inviscid yielding associated with an increase in the irreversible strain that have taken place at the SL stage. This strength gain decays due to damage by irreversible straining during the subsequent ML.

Figure 15 presents test results typically showing the trends illustrated in Fig. 14, obtained from drained TC tests on compacted cement-mixed model Chiba gravel performed under the conditions described in the precedent section. That is Fig. 15(a) presents results from four ML TC tests always at $\sigma_{\mathrm{h}}^{\prime}=20 \mathrm{kPa}$. In two tests, after initial curing for 7 or 9 days under unstressed conditions (i.e., $p^{\prime}=q=0$ ), ML continued toward ultimate failure. In the other two tests, after initial curing for 7 days, the specimens were re-cured at point $B(q=1,000 \mathrm{kPa}$; Fig. 12(a)) for 1 day or 7 days during otherwise ML. The size of the high stiffness stress zone increased with re-curing period. The average stiffness, as well as the elastic Young's modulus, when the stress state was inside this zone also increased with re-curing period. The additional gain in the peak strength obtained by re-curing at an anisotropic stress state was significant and it decayed with an increase in the strain during the subsequent ML. This trend of behaviour is obvious also in the data presented in
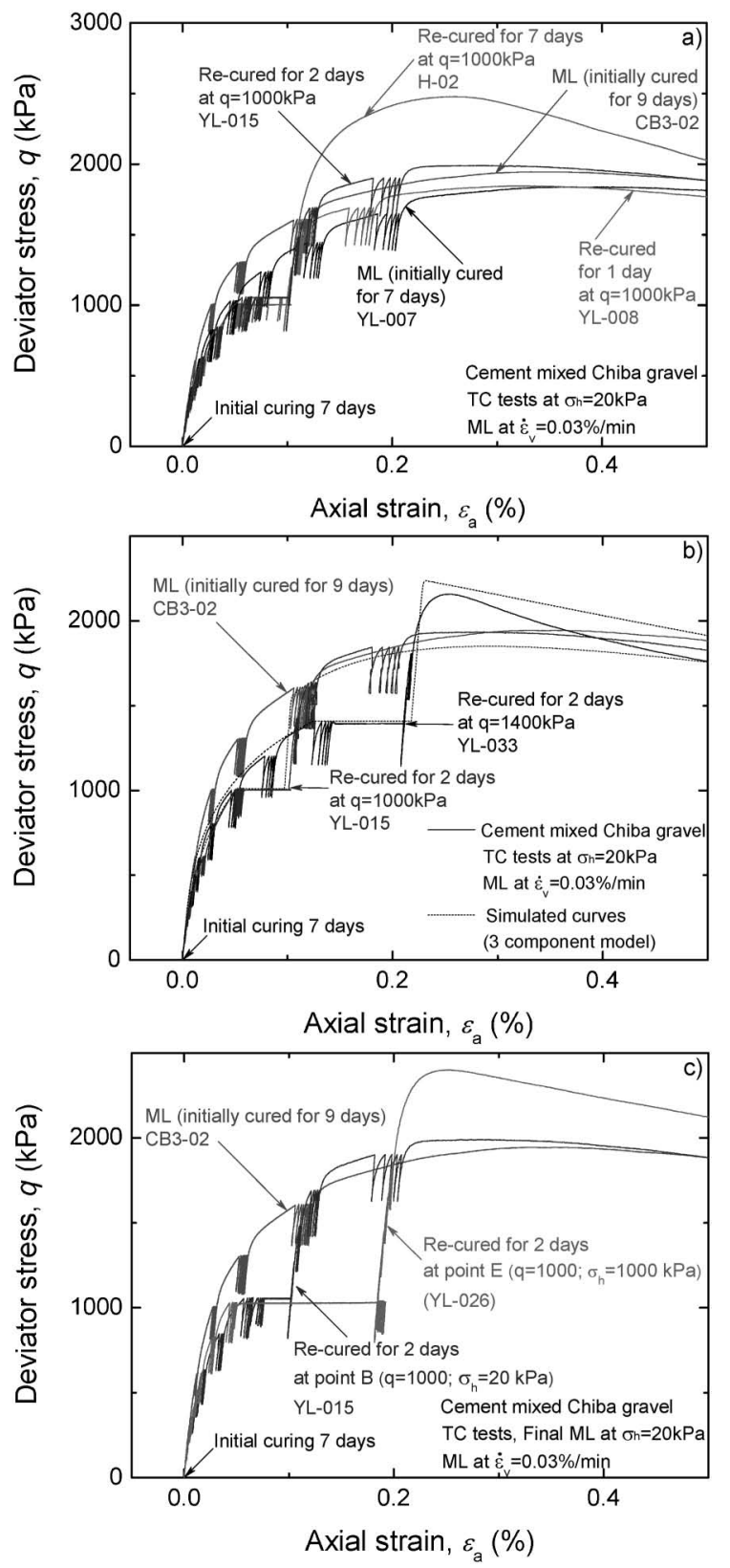

Fig. 15. Effects of re-curing on the subsequent stress-strain behaviour in $\mathrm{ML}$ at $\sigma_{\mathrm{h}}^{\prime}=20 \mathrm{kPa}$, cement-mixed model Chiba gravel (initially cured for 7 days): (a) effect of re-curing period at the same stress state $\left(q=1,000 \mathrm{kPa} ; \sigma_{\mathrm{h}}^{\prime}=20 \mathrm{kPa}\right)$, (b) effect of $q$ during re-curing at $\sigma_{\mathrm{h}}^{\prime}=20 \mathrm{kPa}$ for 2 days and simulations by the three-component model (Tatsuoka et al., 2008) and (c) effect of $\sigma_{\mathrm{h}}^{\prime}$ during re-curing at $q=1,000 \mathrm{kPa}$ for 2 days

Figs. 15(b) and (c), which show the effects of stress state during re-curing on the subsequent stress-strain behaviour at the same $\sigma_{\mathrm{h}}^{\prime}(=20 \mathrm{kPa})$ for the same total curing time $t_{\text {c }}$ (i.e., 9 days). Figure 15(b) compares the stressstrain behavior when the specimens were re-cured at different deviator stresses (i.e., $q=1,000$ or $1,400 \mathrm{kPa}$, points $B$ and $C$ in Fig. 12(a)) for the same period (i.e., 2 days) with the one from a continuous ML test performed after an initial curing for 9 days. The high stiffness stress zone became larger and the peak strength became higher when the specimens were re-cured at a higher deviator 
stress (i.e., at point $C$ ) associated with a larger creep strain during re-curing. Figure 15(c) shows effects of the confining pressure $\left(\sigma_{\mathrm{h}}^{\prime}=20 \mathrm{kPa}\right.$ or $\left.1,000 \mathrm{kPa}\right)$ at the same deviator stress $(q=1,000 \mathrm{kPa})$ (i.e., point $B$ or $E$ in Fig. 12(a)) during re-curing for the same period (2 days) on the subsequent $\mathrm{ML}$ at $\sigma_{\mathrm{h}}^{\prime}=20 \mathrm{kPa}$. At the end of SL stage at $\sigma_{\mathrm{h}}^{\prime}=1,000 \mathrm{kPa}, \sigma_{\mathrm{h}}^{\prime}$ was decreased from $1,000 \mathrm{kPa}$ to 20 $\mathrm{kPa}$ keeping $q$ constant before the restart of ML. The high stiffness stress zone became much larger when recured at a higher $\sigma_{\mathrm{h}}^{\prime}$ (i.e., 1,000 $\mathrm{kPa}$ ) associated with a larger creep strain during re-curing. The positive interaction effect was much larger when re-cured at $\sigma_{\mathrm{h}}^{\prime}=1,000$ $\mathrm{kPa}$. In Fig. 15(b), one of the measured stress-strain
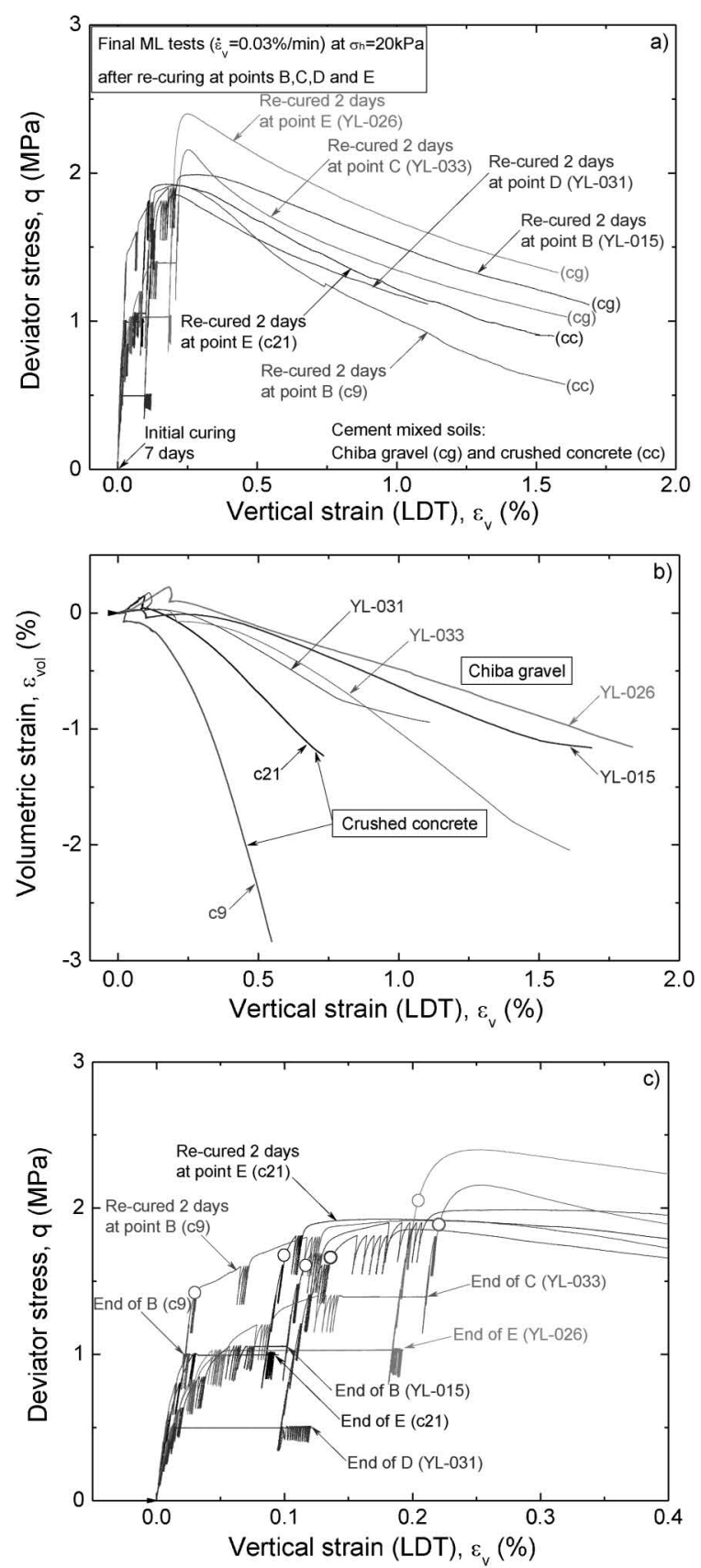

Fig. 16. Effects of re-curing at different stress points $B, C, D$ and $E$ on the final ML behaviour at $\sigma_{\mathrm{h}}^{\prime}=20 \mathrm{kPa}$ for cement mixed model Chiba gravel (cg) and crushed concrete (cc) curves is simulated by the three-component model incorporating ageing effects to demonstrate that the effects of re-curing can be simulated rather accurately. This simulation was performed following the procedure developed for TC test conditions at a fixed confining pressure described in Tatsuoka et al. (2008b). A number of similar simulations are presented in that paper.

\section{Development of Yield Point by Re-curing}

Figures 16-19 show the effects of re-curing for two days at different stress states (i.e., points $B, C, D$ and $E$, Fig. 12(a)) on the relationships among the deviator stress and the vertical and volumetric strains in subsequent drained ML TC at different confining pressures (i.e., 20,
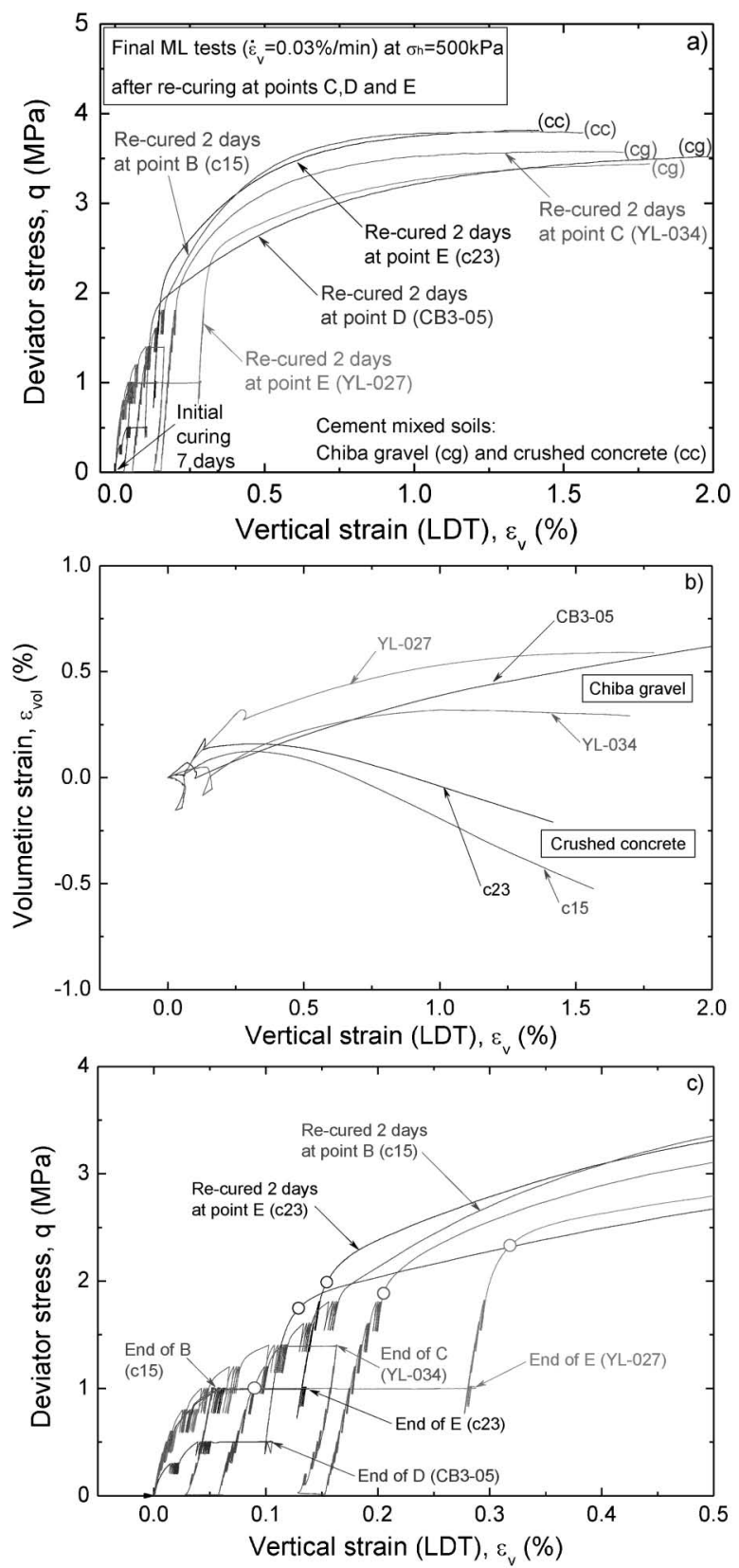

Fig. 17. Effects of re-curing at different stress points $C, D$ and $E$ on the final ML behaviour at $\sigma_{\mathrm{h}}^{\prime}=500 \mathrm{kPa}$ for cement mixed model Chiba gravel (cg) and crushed concrete (cc) 

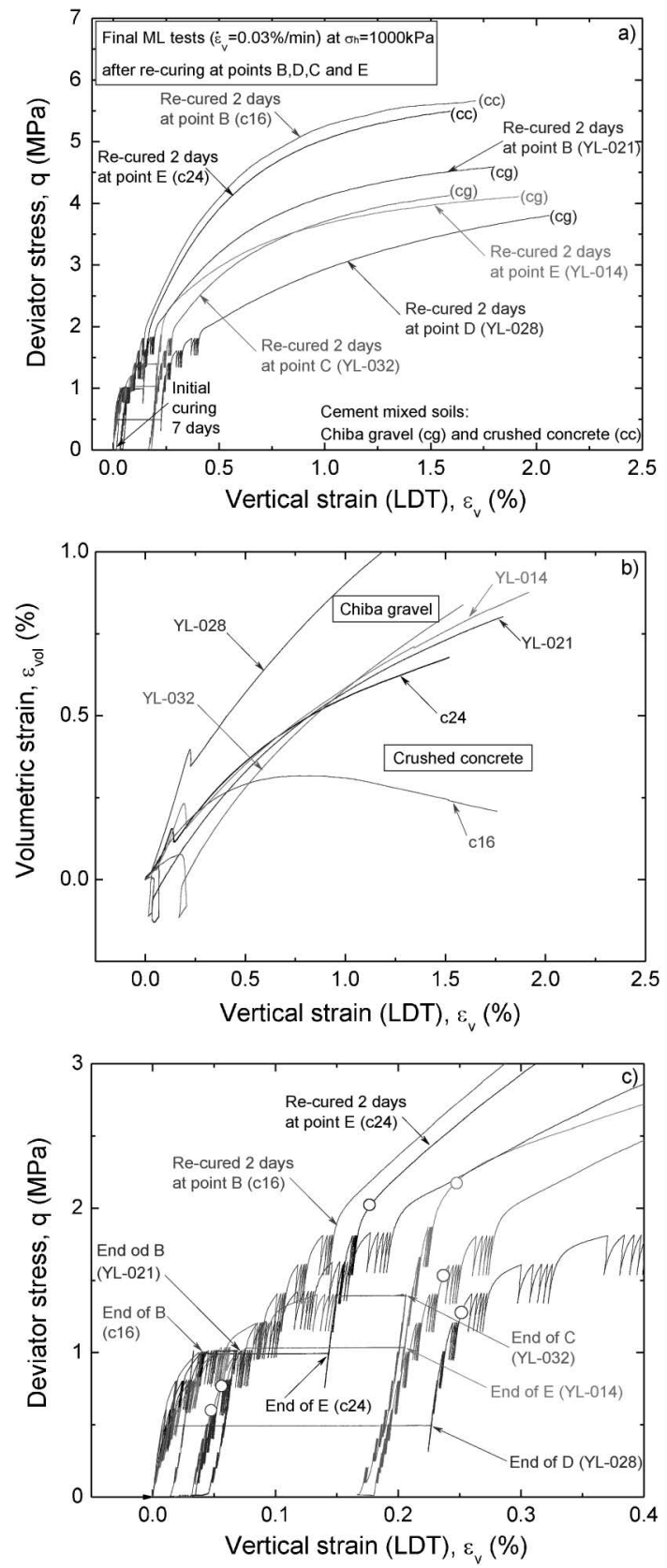

Fig. 18. Effects of re-curing at different stress points $B, C, D$ and $E$ on the final ML behaviour at $\sigma_{\mathrm{h}}^{\prime}=1,000 \mathrm{kPa}$ for cement mixed model Chiba gravel (cg) and crushed concrete (cc)

$500,1,000$ and $1,500 \mathrm{kPa})$. The specimens of cement-mixed crushed concrete (cc) and model Chiba gravel (cg) were initially cured for 7 days under unstressed conditions. The yield points plotted in Figs. 16(c), 17(c), 18(c) and 19(c) were defined by the numerical method described in Figs. 6(a) and (b).

The following trends of behaviour may be seen from these figures:

1) Upon the restart of ML at a constant $\dot{\varepsilon}_{\mathrm{v}}$ with and without changes in $\sigma_{\mathrm{h}}^{\prime}$ after re-curing for two days at a certain fixed stress point, the stress-strain behaviour becomes very stiff for a stress range that ends at a yield point (YP). This stress range $\sigma_{\mathrm{h}}^{\prime}$ becomes larger as the


Fig. 19. Effects of re-curing at different stress points $B, C, D$ and $E$ on the final ML behaviour at $\sigma_{\mathrm{h}}^{\prime}=1,500 \mathrm{kPa}$ for cement mixed model Chiba gravel (cg) and crushed concrete (cc)

$\sigma_{\mathrm{h}}^{\prime}$ value during the final ML in which the YP was defined, decreases more from the value during re-curing.

2) During re-curing for the same period at the same stress state, cement-mixed crushed concrete exhibits much smaller creep strains than cement-mixed model Chiba gravel and more dilative, stiffer and stronger behav- 
iour during the final ML, despite that these two materials were compacted similarly dense relative to the respective maximum dry densities while the compacted dry density of the cement-mixed crushed concrete is much smaller. Considering that model Chiba gravel is one of the high-quality backfill materials used in practice, this result indicates that, when appropriately cement-mixed and well compacted, although the compacted dry density is relatively low, cement-mixed crushed concrete can be used as the backfill to construct soil structures that allow only very small deformation.

3) The effects of positive interaction on the stress-strain behaviour, including the peak strength $\left(q_{\max }\right)$, during the final ML at low $\sigma_{\mathrm{h}}^{\prime}(=20 \mathrm{kPa})$ of cement-mixed model Chiba gravel are significant (Figs. 16(a) and (c)). That is, as the $\sigma_{\mathrm{h}}^{\prime}$ value during the final ML becomes lower than the value during re-curing to a larger extent, the $q_{\max }$ value becomes larger to a larger extent (cf. the $q_{\max }$ values listed in Table 2). This is due likely to the positive effects of cement hydration near and at inter-particle contact points that have developed at higher confining pressure become more effective when sheared at lower confining pressure. Damage to this positive gain can also be noted from the fact that this positive gain is finally erased by large strains that take place subsequently. On the other hand, the effects of this positive interaction are not obvious when sheared at $\sigma_{\mathrm{h}}^{\prime}$ higher than the value during re-curing (Figs. 17-19). It is likely that relatively large irreversible deformation that took place before reaching the peak stress state during the final ML may have erased the positive interaction effects gained during recuring at lower $\sigma_{\mathrm{h}}^{\prime}$.

4) With cement-mixed crushed concrete, the effects of positive interaction on the stress-strain behaviour during the final $\mathrm{ML}$ at a low confining pressure $\left(\sigma_{\mathrm{h}}^{\prime}=20\right.$ $\mathrm{kPa}$ ), which is the same as, or lower than, the value during re-curing, are very small, if any (Figs. 16(a) and (c)), unlike cement-mixed model Chiba gravel. Komoto et al. (2004) and Tatsuoka et al. (2008b) also reported a similar trend with saturated cement-mixed kaolin clay in drained TC. The reason(s) for these different trends, 3) and 4), is (are) not known.

\section{DEVELOPMENT OF YIELD LOCUS}

\section{Comparison of Yield Characteristics between the Two Materials}

Figure 20(a) summarizes the yield points and failure points (i.e., peak states) observed during the final ML at $\dot{\varepsilon}_{\mathrm{v}}=0.03 \% / \mathrm{min}$ when $\sigma_{\mathrm{h}}^{\prime}$ was the same as, or larger than, the value during re-curing for two days at point $B\left(\sigma_{\mathrm{h}}^{\prime}=20\right.$ $\mathrm{kPa}$ ) for the two materials. The failure points are fitted by linear peak strength lines (PSLs; i.e., failure envelop). Figure 20(b) summarizes those observed when $\sigma_{\mathrm{h}}^{\prime}$ was the same as, or smaller than, the value during re-curing for two days at point $E\left(\sigma_{\mathrm{h}}^{\prime}=1,000 \mathrm{kPa}\right)$. The following trends may be seen:
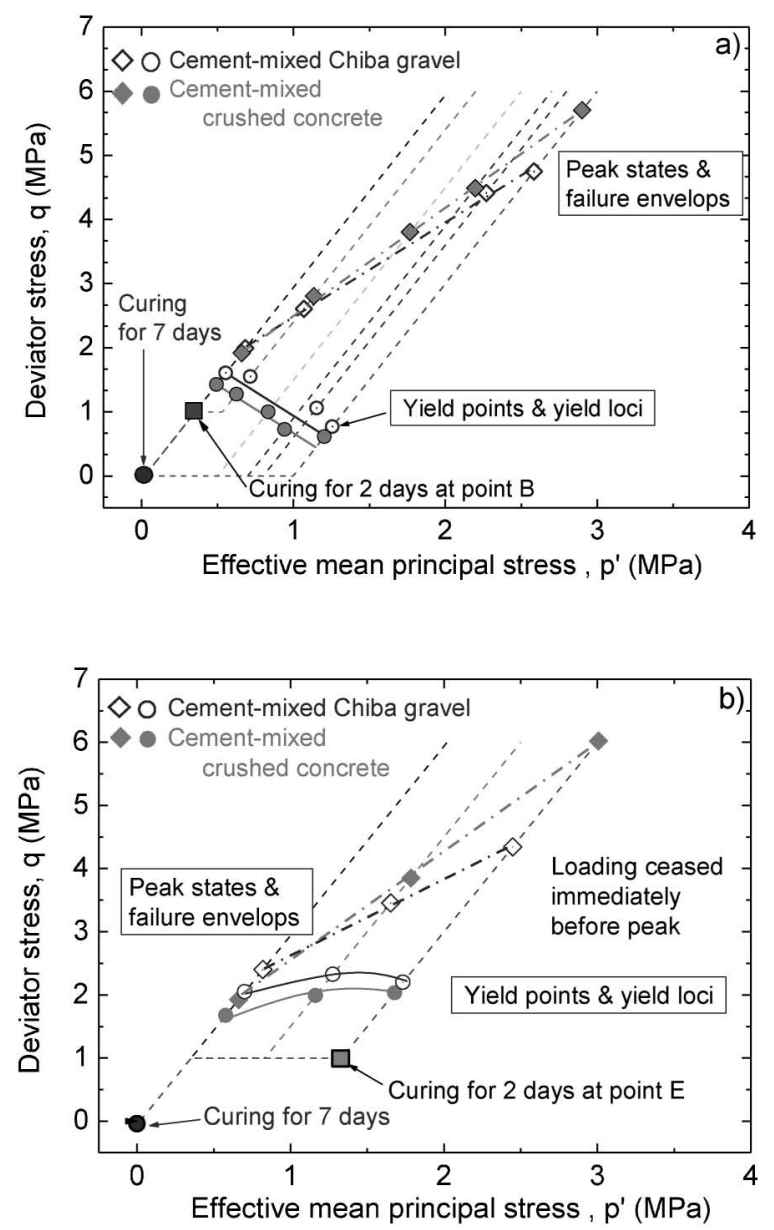

Fig. 20. Yield points and failure points observed by ML at $\dot{\varepsilon}_{\mathrm{v}}=\mathbf{0 . 0 3} \%$ /min when: (a) $\sigma_{\mathrm{h}}^{\prime}$ is unchanged or decreased after curing at point $B$ and (b) $\sigma_{\mathrm{h}}^{\prime}$ is not changed or increased after curing at point $E$

1) With both materials, the patterns of PSL in the two cases are very similar with a high friction angle and a large cohesion intersect, irrespective of different stress states during re-curing.

2) In both cases, the two types of granular materials show similar peak strengths at low confining pressures, $\sigma_{\mathrm{h}}^{\prime}$, while, as $\sigma_{\mathrm{h}}^{\prime}$ increases, cement-mixed crushed concrete becomes notably stronger than cement-mixed model Chiba gravel. On the other hand, in both cases, the yield stress for the same stress history is slightly higher with cement-mixed model Chiba gravel in the whole range of $\sigma_{\mathrm{h}}^{\prime}$ examined. This trend may be explained by larger strains that took place during re-curing with cement-mixed model Chiba gravel. Despite this difference, the pattern of YL is generally similar with these materials.

3) With both materials, the patterns of YL in these two cases are significantly different. That is, the $\mathrm{YL}$ in the first case (Fig. 20(a)) can be rather accurately represented by the condition that $\sigma_{v}^{\prime}=$ constant. This trend is consistent with the test results of chemically stabilized soil reported by Åhnberg (2007), Sugai and Tatsuoka (2003) and Tatsuoka et al. (2008b). On the other hand, the YL in the second case (Fig. 20(b)) can 



Fig. 21. Yield loci and failure envelops observed after re-curing for two days at stress points $B$ and $C$ (low confining pressures) and $D$ and $E$ (high confining pressures): (a) cement-mixed crushed concrete and (b) cement-mixed model Chiba gravel

be represented by a constant deviator stress, $q$, for the first approximation.

The following three related remarks are important. Firstly, the measured yield loci shown in Figs. 20(a) and (b) are those represented in the total stress (i.e., $S_{\mathrm{y}}$ in Fig. 4 in terms of $\sigma$ in Fig. 1), which change by loading rate effects due to the viscous property (Fig. 13). Furthermore, they develop more as the re-curing period becomes longer. Secondly, the peak strengths shown in Figs. 20(a) and (b) are also affected by loading rate effects, as well as ageing effects. Thirdly, with cement-mixed model Chiba gravel, the ageing effect on the peak strength for the same total curing time, $t_{\mathrm{c}}$, may not be unique, but it may be affected by intermediate loading history (i.e., different positive interaction effects), as seen from Figs. 16(a) and (c).

\section{Shape of Yield Locus}

Figures 21(a) and (b) summarize all the yield loci and failure envelops (i.e., PSLs) of the two materials. With both materials, the shape of YL changes gradually but notably as it approaches the failure envelop, from a shape that is closed along the $p^{\prime}$-axis and can be approximated by $\sigma_{\mathrm{v}}^{\prime}=$ constant, when located close to the origin on the $p^{\prime}-q$ plane toward a distorted shape that is open along the $p^{\prime}$-axis and tends to finally join the failure envelop.

In the following, the authors attempt to understand the underlying physical mechanisms for changes in the shape of YL, $S_{\mathrm{y}}$ described above, therefore that of inviscid YL, $S_{\mathrm{y}}^{\mathrm{f}}$ (Fig. 4) and then propose the interactive double-yield concept:

a) Initial $\mathrm{YL}$, approximated by a $\sigma_{\mathrm{v}}^{\prime}=$ constant line: Respective cross-sections in such a biphasic material as a cement-mixed granular material (GM) comprise two components; i) inter-particle contact points, either bound or non-bound; and ii) cement/water-mixture either partially or nearly fully occupying the space between particles. Load applied to the external boundary is supported by these two components. At the initial stage after the cement-mixed GM has been bonded by ageing (i.e., curing) under unstressed conditions, the material has not been damaged by relative movements at inter-particle contact points due to global shearing. It seems that, at the initial stage, the major part of the applied load is supported by bonded inter-particle contacts. That is, the initial YL is mainly a result of the development of the " "bonding mechanism" (by cement-hydration). Then, the yield $\sigma_{1}^{\prime}$ value of the material is controlled mainly by the bond strength at inter-particle contact points that is a function of $\sigma_{1}^{\prime}$. The yield $\sigma_{1}^{\prime}$ value, as well as the peak strength, increases with an increase in the total curing time $t_{\mathrm{c}}$. As the stress state exceeds the initial YL, significant frictional shear stresses start developing at interparticle contact points associated with significant sliding at inter-particle contact points and rotation of particles, which damages the bonding at inter-particle contact points (i.e., de-bonding effects).

b) Evolution of YL until peak stress state: A series of yield loci developed by the "bonding mechanism" associated with strain-hardening and/or ageing from the initial YL to larger ones keeping their shape (i.e., $\sigma_{1}^{\prime}=$ constant) are hereafter denoted as YB (Figs. 22(a) and (b)). On the other hand, as the YL that is actually observed approaches the peak strength line (the PSL), its shape changes from the one of YB to the one having a shape more similar to that of the PSL (Figs. 21 and 22). This trend looks like that the part of YL that is located close to the PSL, is being pushed downward by the PSL as the current implicit YB tends to cross the PSL. It is likely that this shape change is associated with; i) damage to the bonded inter-particle contact points; and ii) the mobilization of frictional resistance (i.e., the "frictional mechanism') at inter-particle contact points, both associated with an increase in the irreversible shear strains. The YL by the "frictional mechanism" is herein denoted as YF. As the location of the implicit YB approaches the PSL, the frictional mechanism becomes more dominant while the bonding mechanism becomes less significant. The yield property of unbound frictional material is characterized basically by the Mohr-Coulomb type criterion with a friction angle and zero cohesion intercept, having an open surface on the $\left(p^{\prime} ; q\right)$ plane (e.g., Tatsuoka and 
Ishihara, 1974; Nawir et al., 2003). As the cohesion is significant with cement-mixed GM, respective YF should have a large cohesion intercept (Fig. 22(b)). It is then reasonable to consider that the yield property of cementmixed GM is controlled by the two mechanisms, bonding and frictional. This consideration is consistent with the fact that cement-mixed GM comprises two components, a granular material and solidified cement/water mixture.

The following considerations on the initial YL are also relevant. Firstly, the characteristic feature that the initial YL is controlled by constant $\sigma_{1}^{\prime}$ is similar to the elastic property of unbound granular materials, which is exhibited when essentially no sliding takes place at inter-particle contact points without rotation of particles. Hardin and Blandford (1989), Hoque and Tatsuoka (1998), Kuwano et al. (1999), Kuwano and Jardine (2002), Ezaoui and Di Benedetto (2009), among others, showed that the elastic Young's modulus defined for a major principal strain increment $\left(d \varepsilon_{1}\right)$ is uniquely controlled by the normal stress acting in the direction of $d \varepsilon_{1}$, while essentially being independent of the normal stresses acting in the orthogonal directions. Secondly, according to Shaw and Sata (1966), the solid materials that engineers are concerned with can be broadly classified into: 1) completely solid materials, such as metals and plastics; 2) unbound particles, such as soils and powders; and 3) porous or cellular materials. It is known that the maximum shear stress or distortion energy criteria are useful in predicting the behavior of completely solid materials under combined stress, and the Mohr-Coulomb envelope with zero cohesion is useful for predicting the behavior of unbound particles. On the other hand, Shaw and Sata (1966), Ashby (1983), Gibson and Ashby (1981) and Deshpande and Fleck (2001) showed that the criterion that $\sigma_{1}=$ constant (i.e., the maximum principal stress criterion) successfully describes the compressive yielding of many polymer foams (i.e., cellular solids). Duttine et al. (2009) showed this is also the case with EPS geofoam. The underlying mechanism may be roughly related to the elastic and/or plastic buckling of the constitutive cells. The $\sigma_{1}=$ constant criterion is also relevant to the initial YL (by the "bonding mechanism") of cement-mixed GM, despite that its origin is different from that of cellular materials. Despite the above, these two types of materials are similar in that both are neither "completely solid materials" nor "unbound particles". When following Shaw and Sata (1966), as the stress state approaches the PSL, the yield property of cement-mixed GM changes from that of porous materials toward that of unbound particles.

It seems that the existing constitutive models for bound geomaterials that can be found in the literature do not deal with the developing process of bonding by ageing. For example, Nova et al. (2003) and Buscarnera and Nova (2009) proposed to modify the original Cam Clay model for unbound soils to the one for bound materials by introducing a yield surface having a unique shape that expands by isotropic (and/or kinematic) volumetric hardening. Therefore, these models are not able to be predicted; i) changes of the shape of YL as observed with cement-mixed GMs in the present study; ii) the expansion of YL due to strain-hardening and ageing process; and iii) positive non-linear interactions between yielding and ageing, which are all essential to capture accurately the yield property of cement-mixed GMs. It is herein proposed to introduce two independent yielding processes (i.e., volumetric by the bonding mechanism and deviatoric by the frictional mechanism) together with a coupling (interactive) mechanism between them (i.e., the interactive double-yield concept) to describe the yield property of cement-mixed GMs. In the multi-laminate framework proposed by Galavi and Schweiger (2009), the rheological model, even though comprising two submechanisms for each integration plan, failed to consider any potential coupling.

\section{Interactive Double-yielding Concept}

As long as the stress state is kept below the current YL (i.e., inside the pseudo-elastic zone), strain increments when subjected to working load increments are kept very small with the tangent stiffness being much higher than the one at the same stress level during continuous largescale yielding by ML (such as test $c$ versus tests $a$ and $b$ in Fig. 14). This trend becomes stronger as YL becomes larger associated with an increase in the strain rate during loading and/or the curing period, respectively, by the viscous property and the positive ageing effects. This is among the most important characteristic features that make relevant the use of cement-mixed GM as the backfill for important soil structures allowing very small instantaneous and residual deformation (such as bridge abutments for highways and railways). The development of a constitutive model that can properly predict the development of YL for a given arbitrary loading history is therefore required to this end. It may be seen from Figs. 21(a) and (b) that, as YL approaches the PSL by longer re-curing at higher deviator stress (e.g., point $C$ ) or higher mean pressure (e.g., point $E$ ), or by larger strain-yielding, the shape of YL changes from the one of the initial YL, developed purely by the "bonding mechanism"' under unstressed conditions (i.e., at point $\left.1\left(p^{\prime}=0 ; q=0\right)\right)$, which can be approximated by a constant $\sigma_{v}^{\prime}$ line (Fig. 22(a)), toward a non-linear one that becomes more distorted. This change in the yield property is associated with the damaging process by debonding together with the development of frictional resistance at the inter-particle contact points caused by irreversible strains. To model this complicated process, an interactive double-yielding concept is introduced assuming that the current YL is defined by interactively combining two current sub-yield loci, YB and YF, which have been developed by two submechanisms, bonding and frictional, as shown in Fig. 22(b) and described as follows:

Yield locus by the bonding mechanism, YB:

$$
\begin{aligned}
& \sigma_{\mathrm{v}_{\mathrm{B}}(\mathrm{YL})}^{\prime}=\sigma_{\mathrm{v}_{\text {_max }}^{\prime}}^{\prime}\left(h, t_{\mathrm{c}}\right) \\
& \sigma_{\mathrm{h}_{-}(\mathrm{YL})}=\sigma_{\mathrm{h}_{-} \text {max }}\left(h, t_{\mathrm{c}}\right)
\end{aligned}
$$

Yield locus by the frictional mechanism, YF: 

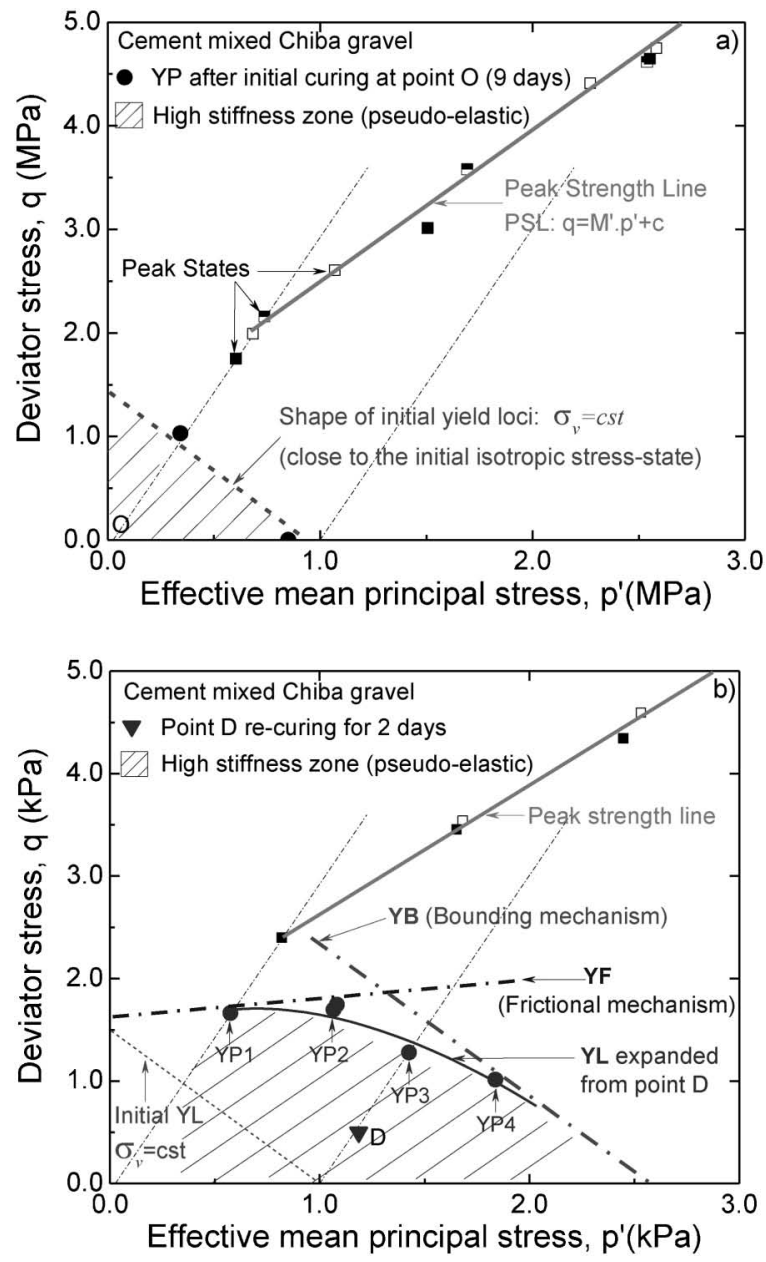

Fig. 22. (a) Lower and upper bounds of YL, initial YL and Peak Strength Line and (b) YL at an intermediate stage developing as a result of interactions between $Y B$ and $Y F$ by two mechanisms

$$
q_{\mathrm{v}_{-}(\mathrm{YL})}=M^{\prime}\left(h, t_{\mathrm{c}}\right) \cdot p_{\mathrm{v}_{-}(\mathrm{YL})}^{\prime}+c^{\prime}\left(h, t_{\mathrm{c}}\right)
$$

where $h$ represents a set of parameters that describe the effects of loading history; $t_{\mathrm{c}}$ is the total curing time; and $M^{\prime}\left(h, t_{\mathrm{c}}\right)$ and $c^{\prime}\left(h, t_{\mathrm{c}}\right)$ are the effective mobilized friction angle and cohesion intercept that are controlled by the frictional mechanism. The parameter $h$ includes, among others, the parameter representing the degradation of bonded internal structure by damage associated with an increase in the irreversible strain, as incorporated in the models proposed by a number of researchers (e.g., Asaoka et al., 2000; Rouainia and Muir Wood, 2000; Kavvadas and Amorosi, 2000; Lee et al., 2004; Kimoto and Oka, 2005). More detailed discussions on this topic are beyond the scope of this paper. It is assumed that, in triaxial tests under two independent principal stress conditions, the bonding mechanism comprises two independent sub-bonding mechanisms that are controlled by irreversible normal strains in the vertical and horizontal directions respectively. Equations (9a) and (9b) dominantly control the yielding in the triaxial tests where either the vertical stress or the horizontal stress changes. Both of the mechanisms (Eqs. (9) and (10)), have been developed by strain-hardening and ageing while interact- ing with each other being affected by damage undergone by the material. They follow respective hardening functions, ageing functions and damage functions that describe $M^{\prime}\left(h, t_{\mathrm{c}}\right), c^{\prime}\left(h, t_{\mathrm{c}}\right), \sigma_{\mathrm{v}_{-} \max }^{\prime}\left(h, t_{\mathrm{c}}\right)$ and $\sigma_{\mathrm{h} \_\max }^{\prime}\left(h, t_{\mathrm{c}}\right)$. Figure 22(b) illustrates a typical intermediate YL that has developed by re-curing at stress point $D$. This YL is a downward-curved envelope of the two types of YL; 1) a YB (by the bonding mechanism), of which the influence is decreasing and fading out as YL approaches the PSL: and 2) a YF (by the frictional mechanism), which is progressively activated more with the slope increasing toward the value of the PSL as YL approaches the PSL. A more detailed description of this model and more systematic numerical analyses of the experimental data than presented in this paper and others are beyond the scope of this paper and will be reported in the near future by the authors.

\section{CONCLUSIONS}

The following conclusions can be derived from the test results and their analysis presented above:

1. A large stress zone bounded by a yield locus (YL) in which highly stiff stress-strain behaviour is observed develops by: i) strain-hardening associated with creep deformation; and ii) positive ageing effects, both taking place during sustained loading at a fixed stress state.

2. The shape of observed YL is different when the confining pressure is increased and decreased after re-curing at a certain stress state and controlled by its location relative to the origin (unstressed condition) and the failure envelope.

3. The shape of the initial YL, observed before the start of any yielding, is approximated by $\sigma_{\mathrm{v}}^{\prime}=\sigma_{1}^{\prime}=$ constant, which is utterly different from that of the failure envelope, which is approximated by the MohrCoulomb failure criterion for cohesive-frictional materials. As the observed YL approaches the failure envelope associated with strain-hardening and/or ageing, its shape gradually changes from the one of the initial YL toward the one of the failure envelop.

4. An interactive double-yielding concept, comprising the bonding and frictional mechanisms, was introduced in order to model the changes in the shape of YL described above.

5. A positive interaction between ageing and inviscid yielding and its decay during subsequent irreversible straining should also be taken into account when modeling the yielding of cement-mixed granular materials.

6. The trends of stress-strain-time behaviour, including the stiffness, peak strength and yield property observed with cement-mixed crushed concrete aggregate are essentially the same as those observed with cementmixed gravelly soil compacted similarly dense relative to the respective maximum dry densities obtained by compaction tests under the same conditions. 


\section{REFERENCES}

1) Åhnberg, H. (2007): On yield stresses and the influence of curing stresses on stress paths and strength measured in triaxial testing of stabilized soils, Canadian Geotechnical Journal, 44, 54-66.

2) Aqil, U., Tatsuoka, F., Uchimura, T., Lohani, T. N., Tomita, Y. and Matsushima, K. (2005): Strength and deformation characteristics of recycled concrete aggregate as a backfill material, Soils and Foundations, 45(4), 53-72.

3) Asaoka, A., Nakano, M. and Noda, T. (2000): Superloading yielding surface concept for highly structured soil behaviour, Soils and Foundations, 40(2), 99-110.

4) Ashby, M. F. (1983): The mechanical properties of cellular solids, Metall. Trans. A, 14A, 1755-1769.

5) Barbosa-Cruz, E. R. and Tatsuoka, F. (2000): Stress-strain properties from elastic behaviour to peak strength of compacted cementmixed sand, Grouting, Soil Improvement, Geosynthetics Including Reinforcement, Finish Geotechnical Society, Proc. 4th Int. Conf. on Ground Improvement Systems, June, Helsinki (eds. by Rathamayer), 3-10.

6) Burland, J. B. (1989): Small is beautiful-the stiffness of soils at small strains, Canadian Geotechnical Journal, 26, 499-516.

7) Buscarnera, G. and Nova, R. (2009): An elastoplastic strainhardening model for soil allowing for hydraulic bonding-debonding effects, Int. Jour. for Numerical and Analytical Methods in Geomechanics, 33, 1055-1086.

8) Dalla Rosa, F., Consoli, C. and Baudet, A. (2008): An experimental investigation of the behavior of artificially cemented soil cured under stress, Géotechnique, 58(8), 675-679.

9) Deshpande, V. S. and Fleck, N. A. (2001): Multi-axial yield behaviour of polymer foams, Acta Materialia, 49, 1859-1866.

10) Di Benedetto, H., Tatsuoka, F. and Ishihara, M. (2002): Timedependent shear deformation characteristics of sand and their constitutive modeling, Soils and Foundations, 42(2), 1-22.

11) Di Benedetto, H., Tatsuoka, F., Lo Presti, D., Sauzeat, C. and Geoffroy, H. (2005): Time effects on the behaviour of geomaterials, Proc. 3rd Int. Sym. on Deformation Characteristics of Geomaterials, IS Lyon 2003, eds. by Di Benedetto et al., Balkema, (2), 59-123.

12) Duttine et al. (2009): Yielding characteristics of EPS-Geofoam under triaxial compression and extension, Soils and Foundations (to be submitted).

13) Ezaoui, A. and Di Benedetto, H. (2009): Experimental measurements of the global anisotropic elastic behaviour of dry Hostun sand during triaxial tests, and effect of sample preparation, Géotechnique, 59(7), 621-635.

14) Galavi, V. and Schweiger, F. (2009): A multilaminate model with destructuration considering anisotropic strength and anisotropic bonding, Soils and Foundation, 49(3), 341-353.

15) Gibson, L. J. and Ashby, M. F. (1981): The mechanics of threedimensional cellular materials, Proc. R. Soc. Lond., A 382, 43-59.

16) Hardin, B. O. and Blackford, G. E. (1986): Elasticity of particulate materials, Jour. of Geotechnical Engineering, 115(6), 788-805.

17) Hayano, K., Sato, T. and Tatsuoka, F. (1997): Deformation characteristics of a sedimentary soft rock from triaxial compression tests rectangular prism specimens, Géotechnique, 47(3), 439-449.

18) Hayano, K., Matsumoto, M., Tatsuoka, F. and Koseki, J. (2001): Evaluation of time-dependent deformation property of sedimentary soft rock and its constitutive modeling, Soils and Foundations, 41(2), 21-38.

19) Hoque, E. and Tatsuoka, F. (1998): Anisotropy in the elastic deformation of granular materials, Soils and Foundations, 38(1), 163-179.

20) Horpibulsuk, S., Katkan, W., Sirilerdwattana, W. and Rachan, R. (2006): Strength development in cement stabilized low plasticity and coarse grained soils: Laboratory and field study, Soils and Foundations, 46(3), 351-366.

21) Jardine, R. J. (1992): Some observations on the kinematic nature of soils stiffness, Soils and Foundations, 32(2), 111-124.

22) Kavvadas, M. and Amorosi, A. (2000): A constitutive model for structured soils, Géotechnique, 50(3), 263-273.

23) Kawasaki, T., Niina, A., Saito, S. and Babasaki, R. (1978): Studies on engineering characteristics of cement-base stabilized soil, Takenaka Technical Report, 19, April, 144-165 (in Japanese).

24) Kimoto, S. and Oka, F. (2005): An elasto-viscoplastic model for clay considering destructuralization and consolidation analysis of unstable behaviour, Soils and Foundations, 45(2), 29-43.

25) Komoto, N., Oka, H., Tatsuoka, F., Koseki, J. and Sato, T. (2004): Deformation and strength characteristics of cemented clay, Proc. 39th Japanese Symposium on Geotechnical Engineering, 239-240 (in Japanese).

26) Kongkitkul, W., Tatsuoka, F., Duttine, A., Kawabe, S., Enomoto, T. and Di Benedetto, H. (2008): Modeling and simulation of ratedependent stress-strain behaviour of granular materials in shear, Soils and Foundations, 48(2), 175-194.

27) Kongsukprasert, L. and Tatsuoka, F. (2005): Ageing and viscous effects on the deformation and strength characteristics of cementmixed gravely soil in triaxial compression, Soils and Foundations, 45(6), 55-74.

28) Kongsukprasert, L. and Tatsuoka, F. (2007): Small strain stiffness and non-linear stress-strain behaviour of cement-mixed gravelly soil, Soils and Foundations, 47(2), 375-394.

29) Kongsukprasert, L., Tatsuoka, F. and Takahashi, H. (2007): Effects of curing period and stress conditions on the strength and deformation characteristics of cement-mixed soil, Soils and Foundations, 47(3), 577-596.

30) Kuwano, R., Connoly, T. M. and Jardine, R. J. (1999): Anisotropic stiffness measurements in a stress-path triaxial cell, Geotechnical Testing Journal, 23(2), 141-157.

31) Kuwano, R. and Jardine, R. J. (2002): On the applicability of crossanisotropic elasticity to granular materials at very small strains, Géotechnique, 52(10), 727-749.

32) Lee, K., Chan, D. and Lam, K. (2004): Constitutive model for cement treated clay in a critical state framework, Soils and Foundations, 44(3), 69-77.

33) Nawir, H., Tatsuoka, F. and Kuwano, R. (2003): Viscous effects on the shear yielding characteristics of sand, Soils and Foundations, 43(6), 33-50.

34) Nova, R., Castellanza, R. and Tamagnini, C. (2003): A constitutive model for bonded geomaterials subject to mechanical and/or chemical degradation, Int. Jour. for Numerical and Analytical Methods in Geomechanics, 27, 705-732.

35) Rouainia, M. and Wood, D. M. (2000): A kinematic hardening constitutive model for natural clays with loss of structure, Geotechnique, 50(2), 153-164.

36) Schrader, E. K. (1996): Compaction of roller compacted concrete, ACI Special publication (SP96-6), 77-101.

37) Shaw, M. C. and Sata, T. (1966): The plastic behavior of cellular materials, International Journal of Mechanical Sciences, 8(7), 469-478.

38) Sugai, M. and Tatsuoka, F. (2003): Ageing and loading rate effects on the stress-strain behaviour of a cement-mixed soft clay, Proc. 3rd Int. Sym. on Deformation Characteristics of Geomaterials, IS Lyon 2003, eds. by Di Benedetto et al., Balkema, (1), 627-635.

39) Tatsuoka, F. (2004): Cement-mixed soil for Trans-Tokyo Bay Highway and railway bridge abutments, Geotechnical Engineering for Transportation Projects, Proc. of GeoTrans 04, GI, ASCE, Los Angels, ASCE GSP 126, eds. by Yegian and Kavazanjian, 18-76.

40) Tatsuoka, F. (2007): Inelastic deformation characteristics of geomaterial, Special Lecture, Soil Stress-Strain Behavior: Measurement, Modelling and Analysis eds. by Ling et al., Proc. of the Geotechnical Symposium, Roma, March, 2006, 1-109.

41) Tatsuoka, F. and Ishihara, K. (1974): Yielding of sand in triaxial compression, Soils and Foundations, 14(2), 51-65.

42) Tatsuoka, F. and Kobayashi, A. (1983): Triaxial strength characteristics of cement-treated clay, Proc. 8th European Conf. on SMFE, (1), 421-426.

43) Tatsuoka, F. and Shibuya, S. (1991): Deformation characteristics of soils and rocks from field and laboratory test, Proc. 9th Asian Regional Conf. on SMFE, Bangkok, (2), 101-170. 
44) Tatsuoka, F., Uchida, K. and Ouchi, T. (2000): Geotechnical engineering aspects of Trans-Tokyo Bay Highway project, Proc. GeoEng2000, Melbourne, I, 996-1024.

45) Tatsuoka, F., Ishihara, M., Di Benedetto, H. and Kuwano, R. (2002): Time-dependent shear deformation characteristics of geomaterials and their simulation, Soils and Foundations, 42(2), 103-129.

46) Tatsuoka, F., Di Benedetto, H. and Nishi, T. (2003): A framework for modelling of the time effects on the stress-strain behaviour of geomaterials, Proc. 3rd Int. Sym. on Deformation Characteristics of Geomaterials, IS Lyon 2003, eds. by Di Benedetto et al., Balkema, 1135-1143.

47) Tatsuoka, F., Tateyama, M., Aoki, H. and Watanabe, K. (2005): Bridge abutment made of cement-mixed gravel backfill, Ground Improvement, Case Histories, Elsevier, Geo-Engineering Book Series, eds. by Indradratna and Chu, 3, 829-873.

48) Tatsuoka, F., Tomita, Y., Lovati, L. and Aqil, U. (2006): Crushed concrete aggregate as a backfill material for civil engineering soil structures, Design and Construction of Pavements and Rail Tracks, Geotechnical Aspects and Processed Materials, Proc. of Workshop of TC3 of the ISSMGE, 16th ICSMGE, Osaka, eds. by Correia et al., Taylor and Francis, 139-157.

49) Tatsuoka, F., Di Benedetto, H., Enomoto, T., Kawabe, S. and Kongkitkul, W. (2008a): Various viscosity types of geomaterial in shear and their mathematical expression, Soils and Foundations, 48(1), 41-60.

50) Tatsuoka, F., Di Benedetto, H., Kongkitkul, W., Kongsukprasert, L., Nishi, T. and Sano, Y. (2008b): Modeling of ageing effects on the elasto-viscoplastic behaviour of geomaterial, Soils and Foundations, 48(2), 155-174.

51) Tatsuoka, F., Sano, Y., Iguchi, Y. and Kume, H., Kongkitkul, W. and Di Benedetto, H. (2008c): Modeling of ageing effects on the elasto-viscoplastic stress-strain behaviour of geomaterial, Deformational Characteristics of Geomaterials, Proc. IS Atlanta, eds. by Burns, Mayne and Santamarina, 1, 467-474.

52) Tatsuoka, F., Hirakawa, D., Nojiri, M., Aizawa, H., Nishikiori, H., Soma, R., Tateyama, M. and Watanabe, K. (2009): A new type integral bridge comprising geosynthetic-reinforced soil walls, Geosynthetics International, IS Kyushu 2007 Special Issue, 16(4).

53) Terashi, M., Tanaka, H., Mitsumoto, T., Niidome, Y. and Honma, S. (1980): Fundamental properties of lime and cement treated soils (second report), Report of the Port and Harbor Research Institute, 19(1), March, 33-62 (in Japanese).

54) Watanabe, K., Tateyama, M., Jiang, G., Tatsuoka, F. and Lohani, T. N. (2003): Strength characteristics of cement-mixed gravel evaluated by large triaxial compression tests, Proc. 3rd Int. Symp. on Deformation Characteristics of Geomaterials, IS Lyon 03, Balkema, 683-693. 